\title{
Powder-based laser hybrid additive manufacturing of metals: a review
}

\author{
Amaia Jiménez $^{1,2} \cdot$ Prveen Bidare $^{1} \cdot$ Hany Hassanin $^{3} \cdot$ Faris Tarlochan $^{4} \cdot$ Stefan Dimov ${ }^{1} \cdot$ Khamis Essa $^{1}$
}

Received: 25 August 2020 / Accepted: 1 March 2021 / Published online: 19 March 2021

(C) The Author(s) 2021

\begin{abstract}
Recent advances in additive manufacturing (AM) have attracted significant industrial interest. Initially, AM was mainly associated with the fabrication of prototypes, but the AM advances together with the broadening range of available materials, especially for producing metallic parts, have broaden the application areas and now the technology can be used for manufacturing functional parts, too. Especially, the AM technologies enable the creation of complex and topologically optimised geometries with internal cavities that were impossible to produce with traditional manufacturing processes. However, the tight geometrical tolerances along with the strict surface integrity requirements in aerospace, biomedical and automotive industries are not achievable in most cases with standalone AM technologies. Therefore, AM parts need extensive post-processing to ensure that their surface and dimensional requirements together with their respective mechanical properties are met. In this context, it is not surprising that the integration of AM with post-processing technologies into single and multi set-up processing solutions, commonly referred to as hybrid AM, has emerged as a very attractive proposition for industry while attracting a significant R\&D interest. This paper reviews the current research and technology advances associated with the hybrid AM solutions. The special focus is on hybrid AM solutions that combine the capabilities of laser-based AM for processing powders with the necessary post-process technologies for producing metal parts with required accuracy, surface integrity and material properties. Commercially available hybrid AM systems that integrate laser-based AM with post-processing technologies are also reviewed together with their key application areas. Finally, the main challenges and open issues in broadening the industrial use of hybrid AM solutions are discussed.
\end{abstract}

Keywords Hybrid manufacturing $\cdot$ Additive manufacturing $\cdot$ Laser $\cdot$ Powder $\cdot$ Post-processing

\section{Introduction}

The advances of additive manufacturing (AM) technology have broaden its application areas and AM is becoming a viable option for producing completely functional metal parts. In fact,

Amaia Jiménez and Prveen Bidare are joint first authors

Prveen Bidare

p.bidare@bham.ac.uk

Khamis Essa

K.E.A.Essa@bham.ac.uk

1 School of Mechanical Engineering, University of Birmingham, Birmingham, UK

2 TECNUN Escuela de Ingeniería, Universidad de Navarra, Manuel de Lardizábal 15, 20018 San Sebastián, Spain

3 School of Engineering, University of Liverpool, Liverpool, UK

4 Department of Mechanical and Industrial Engineering, College of Engineering, Qatar University, 2713 Doha, Qatar metal AM is currently applied in the most demanding industrial sectors, i.e. aerospace [1], energy [2], defence [3], and biomedical $[4,5]$. The technology allows the generation of parts with a complex topologically optimised geometry with internal cavities that were impossible to create with traditional manufacturing processes. However, tight tolerances and strict surface integrity requirements cannot be achieved by employing standalone AM technologies in most cases. Therefore, AM parts commonly require some post-processing to meet requirements associated with surface finish, dimensional tolerances and mechanical properties. So, it is not surprising that the integration of AM with post-processing technologies into single and multi set-up processing solutions, commonly referred to as hybrid AM, has emerged as a very attractive proposition for industry while attracting a significant $R \& D$ interest.

In this context, the paper is focused on hybrid manufacturing solutions that combine the capabilities of laser-based AM technologies for consolidating metal powders with postprocessing ones, e.g. machining, heat treatments and surface finishing, to produce parts with required accuracy, surface 
integrity and material properties. This includes both the integration of post-processing technologies in the same set-up with the laser-based AM processes but also sequentially in multi set-up hybrid solutions. In order to consider multi setup solutions as hybrid, special fixtures or geometrical references should be employed to minimise part-positioning errors. Such single and multi set-up hybrid AM solutions offer capabilities for producing metal parts with higher complexity without compromising their accuracy, surface integrity and material properties. The potential of such hybrid AM manufacturing routes has attracted a significant industrial and research interest. The R\&D efforts were focused both on broadening their application areas and on investigation and further development of their capabilities. This is evident from the constantly growing number of the published papers in this field over the past 10 years as shown in Fig. 1.

Additionally, in Fig. 2, it is shown that among the different heat sources employed in additive manufacturing processes, laser power has gained the highest interest from the research community ( $31 \%$ of published research works are focused on laser-based additive manufacturing processes). Considering the growing importance of laser-based additive manufacturing technologies, as mentioned above, the present work will summarise relevant research works regarding the hybrid additive manufacturing that combines laser additive manufacturing and post-processing techniques.

The structure of this review paper is as follows. The next section provides an overview of available AM technologies for producing metal parts, and then the most common laserbased AM processes for consolidating metal powders are reviewed. In particular, investigations on their limitations and respective post-processing requirements for producing metal parts are reported. Then, the research on postprocessing technologies that are usually integrated with laser-based AM processes into single and multi-setup AM solutions is reviewed. Next, the benefits offered by different post-processing technologies in addressing the shortcomings of metal AM parts are discussed based on the reported

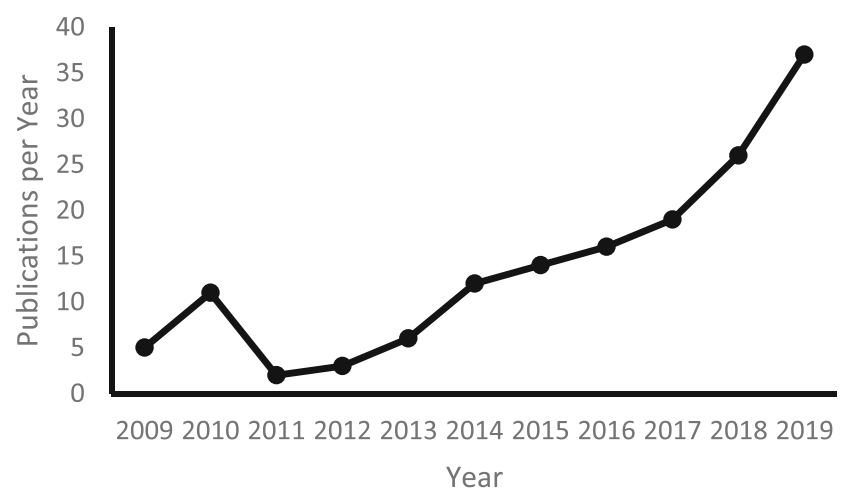

Fig. 1 The number of published papers on hybrid additive manufacturing over the last 10 years, [6]

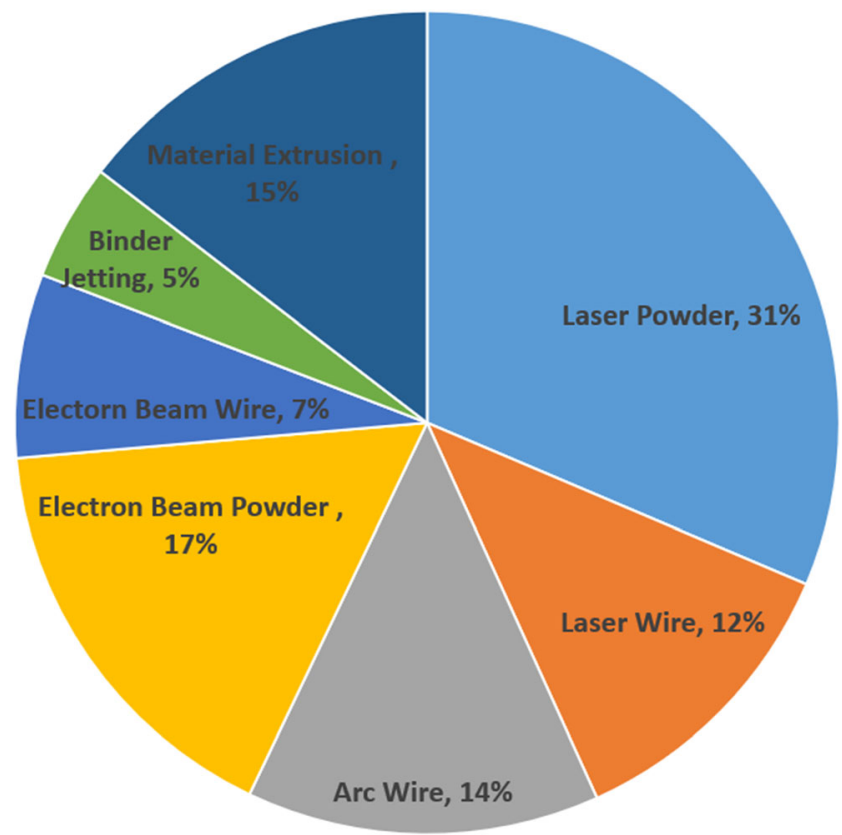

Fig. 2 Additive manufacturing articles published in 2019, [6]

research. Section 5 reviews the commercially available hybrid AM technologies, with specific focus on their advantages and limitation. Section 6 provides an overview of relevant research on main application areas for the hybrid AM manufacturing solutions. Next, Section 7 discusses the main challenges in broadening the use of hybrid AM routes for producing metal parts with required complexity and quality. Finally, conclusions are made about the reviewed hybrid AM routes.

\subsection{Metal additive manufacturing processes}

AM encompasses all technologies for producing parts in layer-by-layer fashion directly from CAD models. Initially, AM technologies were mostly applied for fabricating prototypes quickly that can be used for design verification and marketing purposes. They became quickly indispensable in many application areas. However, they were still just physical models that were not supposed to fulfil any functional requirements and therefore were commonly made from non-metallic materials, such as thermoplastics, resins and ceramic powders [7]. Meanwhile, the advances of AM technologies in the last two decades, especially for building metallic parts, made possible the manufacture of functional components and thus enabling the so-called direct digital manufacturing [8].

Metallic parts can be produced by employing mainly five different categories of AM technologies, known as material extrusion, powder bed fusion, direct energy deposition, binder jetting and laminated object manufacturing (LOM) $[9,10]$. Each category includes metal AM technologies that employ different methods for producing physical models, in particular: 
- Material extrusion. Thermoplastic filaments or rods loaded with a metal powder are extruded through a heated nozzle to build metal parts layer by layer. Afterwards, the thermoplastic content in the printed green parts is removed chemically and/or thermally that is followed by a sintering process to produce metal parts $[5,11]$.

- Powder bed fusion (PBF). The process employs a heat source, e.g. a laser or an electron beam, to fuse or melt the powder particles layer by layer. The energy beam is applied to a small region of a powder bed that incrementally drops down upon the completion of each layer. Depending on the processing temperature, the powder consolidation is done by sintering process or melting. Direct metal laser sintering (DMLS), selective laser melting (SLM) and electron beam melting (EBM) are the most widely used technologies that fall in this AM category [5, 11].

- Direct laser deposition (DLD). The process employs focused thermal energy, e.g. a laser source or arc plasma, to fuse materials by melting. In particular, metal powder or wires are fed through a nozzle at the focal spot and deposited to a heated substrate layer by layer according to a predefined path. In this AM category, laser engineering net shaping (LENS) or direct metal deposition (DMD) technologies are noteworthy $[11,12]$.

- Binder jetting. A binder agent is selectively deposited onto a metal powder bed to glue particles together layer by layer. Similar to the material extrusion, the binder content in the printed part is removed chemically through a debinding step and then the part is consolidated by sintering. Parts created using this method are not fully dense, and therefore, an infiltration is required to fill the porosity with metal powder [11].

- Laminated object manufacturing (LOM). It is a technique that uses ultrasonic or laser energy source to stack previously cut metal sheets to form a three-dimensional object [13]. This technology is also referred to as sheet lamination (SL).

The schematic diagram shown in Fig. 3 presents a classification of existing AM technologies for producing metal parts. In the figure, the processes that fall within the scope of this review are highlighted. As was already mentioned, this review is focused on single and multi-setup hybrid AM routes that employ laser-based AM process to consolidate metal powders.

In addition to the four metal AM technologies discussed so far, another technology called cold spray additive manufacturing (CS or CSAM) has been attracting some research interest. $\mathrm{CS}$ is a material deposition process that was initially developed for coating/cladding purposes but has recently been employed as a metal AM process to build and repair components [14]. Materials are deposited by accelerating fine powder particles to a critical speed by employing a highvelocity compressed gas stream that upon the impact on the substrate, a metallurgical bond and mechanical interlocks are formed to produce parts layer by layer. Laser-assisted cold spray has also been subjected to investigation as an improved alternative to the CS process. Bray et al. [15] developed a system to deposit powder particles through CS in a substrate heated by laser diode and achieved deposits with densities higher than 99\%. However, the CS process is outside the scope of this review paper and will not be analysed in the following sections.

It should be noted that among all metal AM technologies, the laser-based PBF (LPBF) process has attracted the highest industrial interest due to the relatively good accuracy and surface finish that can be achieved. However, the type of parts that can be produced with this technology is limited by the size of the powder bed. Therefore, DLD or also referred to as laserbased direct energy deposition (DED) has gain significant industrial interest, too, because of its higher build rates and bigger size of the parts that can be produced. However, such flexibility is at the expense of accuracy and surface integrity of produced parts and therefore commonly they require extensive post-processing [16]. Considering the industrial interest in the LPBF and DLD technologies $[17,18]$ and also their often integration in hybrid AM solutions, their fundamentals and a review of relevant research on these two technologies are presented in the next section.

\subsection{Laser-based additive manufacturing processes}

\subsubsection{Laser-based powder bed fusion}

This technology is currently being used for the manufacture of mostly high-value parts. LPBF is an AM technology that employs continuous-wave laser sources to melt and fuse particles selectively onto a powder bed and thus creating three-dimensional parts layer by layer. When the particles are melted, viscous flow due to a surface tension joins them together into a melt pool. Then, the energy in the melt pool is transferred to the surrounding powder through conduction, radiation and convection $[19,20]$. After the selective consolidation of areas on each layer, the powder bed is lowered and the next layer of powder is spread and thus successive layers are processed to create fully dense 3D parts [21-23]. Figure 4 shows a schematic diagram of the LPBF process.

In LPBF, process parameters, namely scan strategy, laser spot diameter, laser power, scan speed, scan line spacing and the thickness of the powder layer, have to be optimised in order to obtain the best results in terms of porosity and mechanical properties of the consolidated powder [22, 24, 25]. Laser power is considered the most influencing parameter in regards to the density (or porosity) of the final part [26]. Also, 


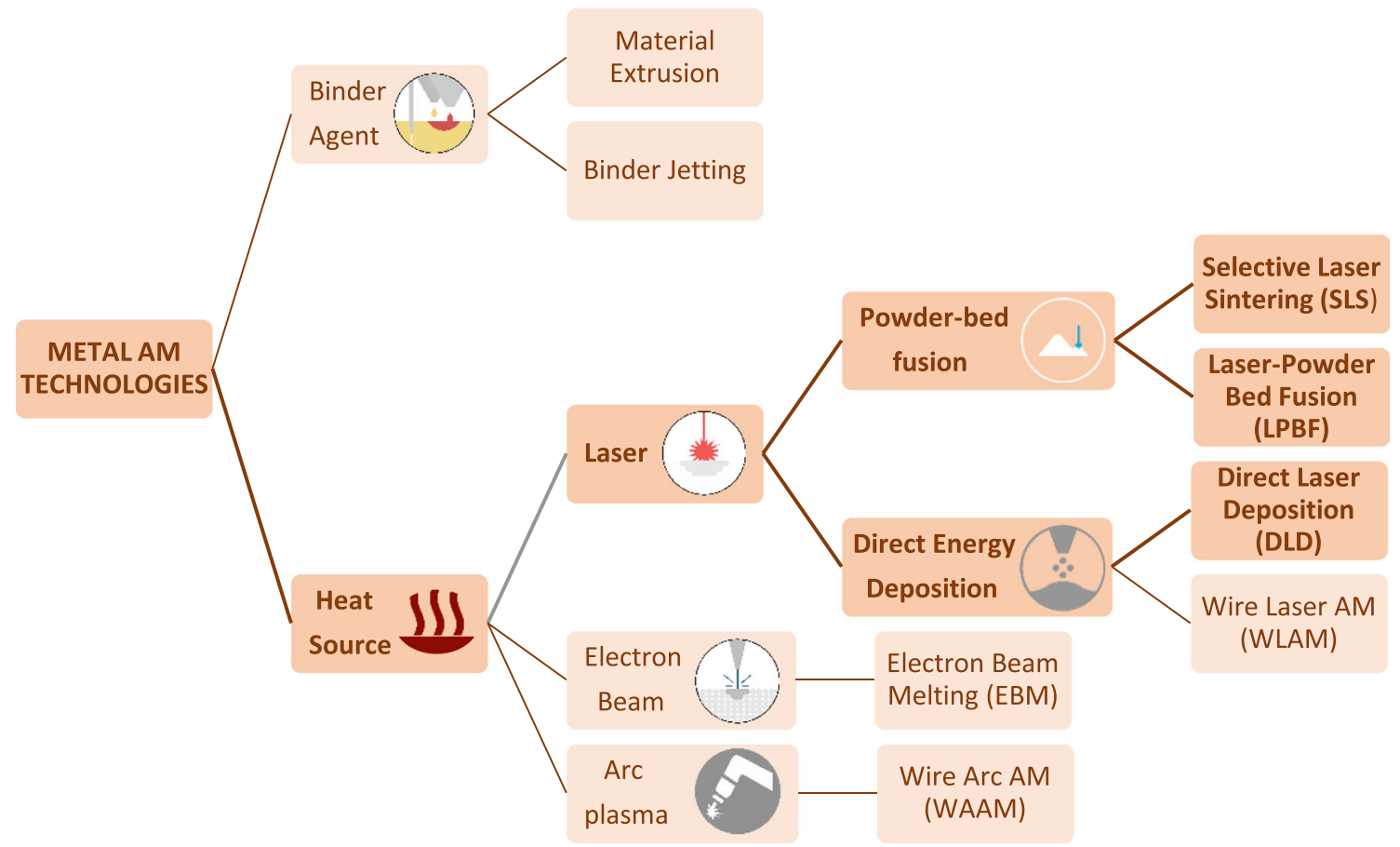

Fig. 3 Classification of metal AM technologies

powder characteristics, i.e. chemical constituents, particle shape and size and distribution, are a factor affecting the final part quality [24]. In fact, it is possible to assess the laser heat input by using the so-called "energy density function" as follows [25]:

$\Psi=\frac{P}{\nu \cdot h \cdot t}$ where $P$ and $v$ are the laser power and scan speed, respectively, $h$ is the scan spacing, and $t$ is the layer thickness. Some studies have shown that the optimum energy density for a given material can be found and thus producing parts with as low as possible porosity. In addition to the abovementioned process parameters, gas flow direction and flow rate in the build chamber have been identified as factors affecting the part quality [27]. Insufficient gas flow rates and

Fig. 4 Graphical explanation of the LPBF process
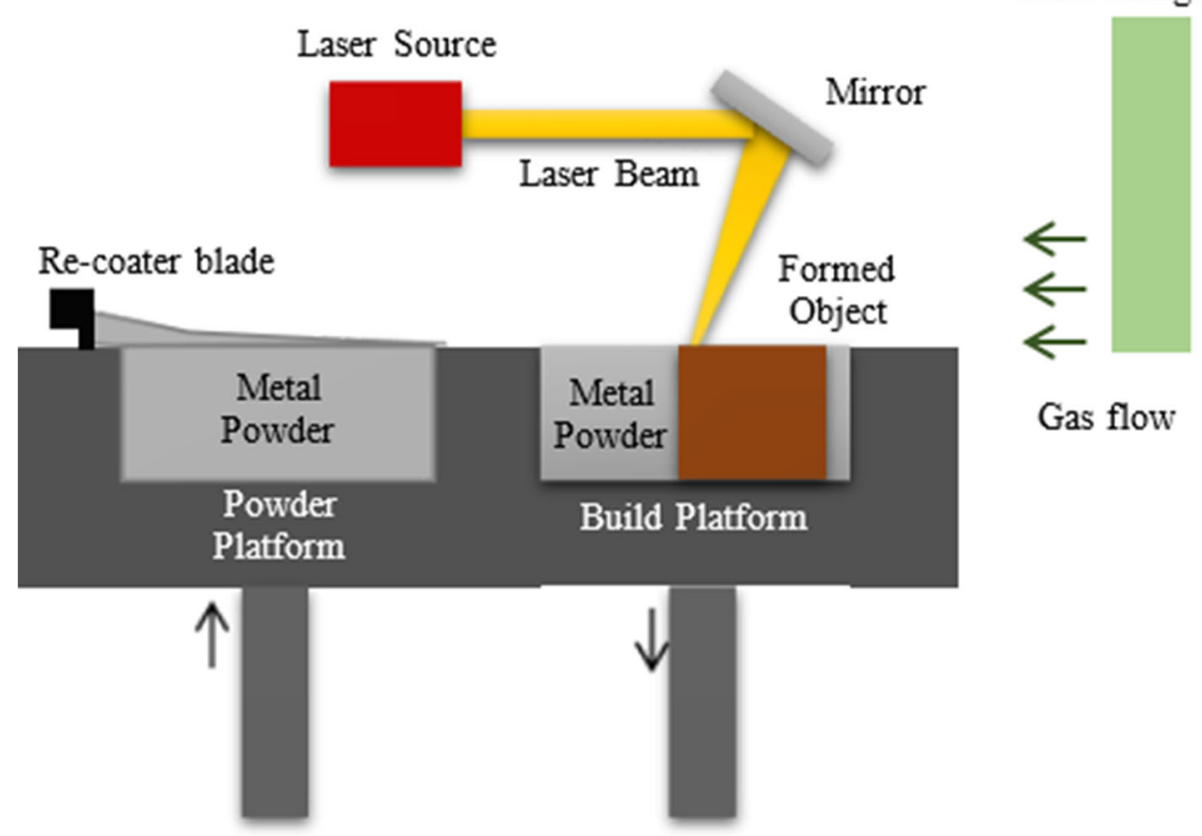

Flow straightener 
inappropriate flow directions could lead to part delamination. Furthermore, the height of the flow straightener from the powder bed and the type of the used shielding gas also affect the build quality [28].

There is a wide range of alloys available for LPBF. Among them, stainless steel (AISI 316L), aluminium, titanium and their alloys, e.g. AlSi10Mg and Ti6Al4V, and Ni-based alloys, e.g. Inconel 718 , are the most widely used materials. Depending on the materials employed, different issues could arise during the LPBF process. For example, when aluminium or its alloys are used, a major issue that can affect the process is the material oxidation that could occur due to the presence of oxygen in the build chamber [29].

The available materials allow the LPBF process to be used in different industrial applications. Figure 5 shows some examples of LPBF parts produced for aerospace, i.e. a bracket and a pump, and automotive, i.e. an air duct, applications.

Recently, a number of process advances have been reported. In particular, the development of a gas atomised powder with particles that are spherical, have a higher flowability and a higher packing density can be achieved [34]. As the long build times and high part costs are some of the main issues preventing the broader use of the LPBF technology, a research to improve the process productivity and also to reduce residual stresses through the use of quad laser systems was reported [35]. In addition, LPBF systems that integrate powder handling/cleaning and part post-processing in the same build chamber have been developed and thus underpins the use of this AM technology for series production [36]. Other process improvements include advances in gas flow systems that use sub-atmospheric pressure in the build chamber which enables better quality parts at lesser laser powers ensuring reduced overall energy consumption [37]. Also, the development of process monitoring tools has been an important R\&D topic recently for researchers and manufacturing companies as a way both to understand better the underlying laser-material interactions during the process and thus improving the process control [38]. In particular, the chamber conditions, i.e. build plate temperature, ambient temperature, pressure oxygen concentration, etc., should be monitored as they have a significant effect on process behaviour and can lead to the occurrence of part defects [39]. Recently, the development of advanced monitoring systems has been reported that allow some important process parameters, such as laser power, porosity, meltpool status, powder layer distribution on the build surface and temperature, to be controlled [40, 41].

The LPBF process offers some advantages with respect to other manufacturing processes. Especially, complex geometries can be built with this technology and parts with relatively small features and internal cavities can be created, too, with this process. It enables the manufacture of lightweight parts, i.e. topology optimised ones and parts with lattice structures, and therefore is a very attractive option for a number of applications in the aerospace industry. Additionally, the LPBF parts have high specific strength and stiffness [42, 43].
Fig. 5 Industry applications of the LPBF technology. a Spider bracket. b Manifold (photo courtesy of Renishaw) [30]. c A380 fuel connector [31]. d, e Topology optimized aerospace brackets [32, 33]

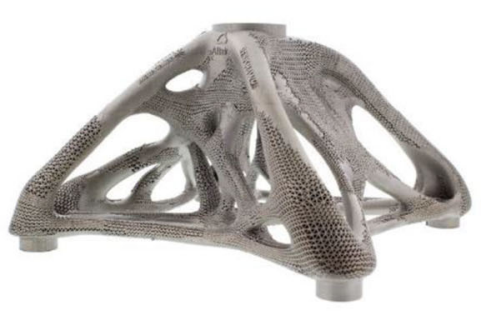

(a)

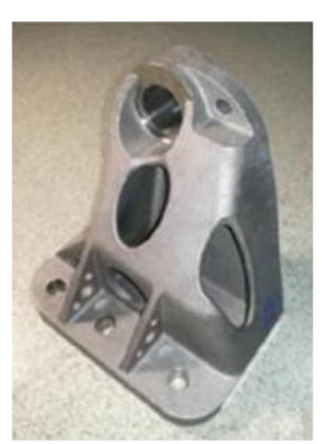

(d)

)

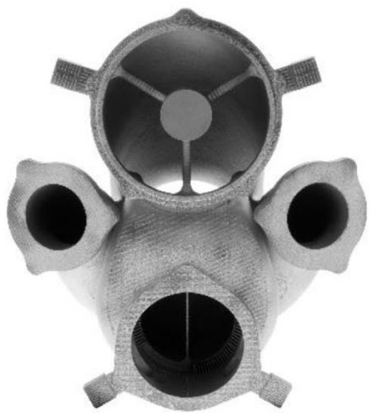

(b)

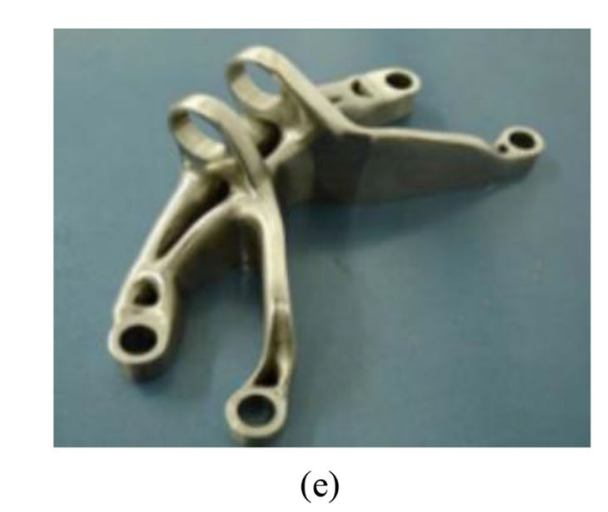

(e)

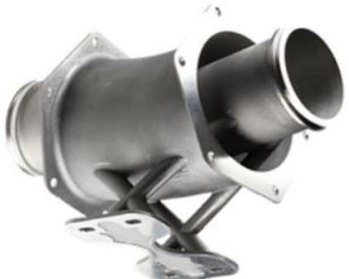

(c) 
However, the LPBF technology has some limitations, too. Surface roughness of produced parts is a major issue for the broader use of this layer-by-layer process that leads to the widely known "staircase effect", particularly visible on sloping edges. Apart from process parameters, powder size is another factor that affects the resulting surface finish. When smaller particles are employed and a layer thickness is reduced, a better surface finish can be obtained. However, this is at expense of manufacturing time and cost [44]. In addition, as consequence of the high heat load during the melting process, there is a high thermal gradient in the built parts that lead to higher residual stresses and a deterioration of their fatigue behaviour [45]. LPBF has some other inherited issues that can affect the process, such as the porosity and the shrinkage of built parts. Due to liquid to solid transformations and to the inhomogeneous cooling to room temperature in the solid state, shrinkage and accumulation of residual stresses occur. Regarding porosity, instability of the melt pool [46], lack of fusion between powder particles [47] and a narrow particle size distribution can reduce the packing density $[48,49]$ that together with scanning strategies can promote the manufacture of low-density LPBF parts $[45,50]$. Other issues include powder oxidation that could occur due to the presence of oxygen in the build chamber during the process [51]. Figure 6 depicts disconnection in LPBF parts due to residual stresses while porosity, voids and lack of fusion defects are shown in Fig. 7.

\subsubsection{Direct laser deposition}

The DLD technology employs a focused laser beam to fuse materials in the form of metal wires and/or powder onto a building platform and thus producing parts layer by layer [54]. As the focus of the paper is on powder-based AM processes, only the relevant research on DLD of powders is reviewed. During the DLD process, some of the laser irradiation is absorbed by the substrate on which the powder particles are delivered through a nozzle and thus a controlled melt pool is created in the laser-material interaction area [55]. Additionally, an inert gas, i.e. argon, is delivered onto the deposition area in order to minimise any metal oxidation. The process is graphically shown in Fig. 8.

The DLD system can be attached to a robot arm or integrated into a multi-axis machine so that the nozzle can follow a specific path to generate the desired geometry layer by layer. DLD is commonly employed for applying thick coatings of workpiece and also for repairing worn or damaged parts. The latter is of growing interest in the automotive and aerospace industries due to the cost saving that the DLD process can offer.

Similar to LPBF, powder characteristics have a great impact on the quality and properties of the DLD manufactured parts. Chemical compositions of powders, particle size, distribution and morphology together with laser parameters, i.e. laser power, powder feed rate and scanning speed, have to be optimised in order to produce parts with required physical and mechanical properties [56]. Another important DLD processing parameter is the hatching or scanning strategy that defines the path of the powder deposition head. The microstructure and mechanical properties of the DLD parts can be controlled by varying the hatching strategy [57]. Additionally, the nozzle inclination angle and the set focal plane for the laser beam are important factors affecting the properties of the DLD parts [58].

The powders used for the DLD process are similar to those utilised in the LPBF process. For example, the DLD is commonly used to process the following materials: nickel-based alloys (In625, In718, In738, In713, In939, CM-247LC, Nimonic 263, Hastelloy X, Hastelloy C-276, Waspaloy, Haynes 230, MarM247), titanium alloys (Ti6Al4V, Ti-6-24-2, Ti-6-2-4-6, CP Ti), aluminium and its alloys (4047, 6061, 7050, 7075, AlSi7Mg, AlSi10Mg, AlSi12), iron-based alloys (17-4PH, H13, 304L, 316L, 420SS, PH 138 Mo, 155PH, AISI 4140), cobalt-based alloys (Stellite21, CM-64, $\mathrm{Co} 6, \mathrm{CoCr})$ and Copper-based $(\mathrm{Cu}-\mathrm{Ni})$ and iron-nickelchromium alloy (A286) [59]. The processing of such powders with the DLD technology is an important enabler for producing and repairing complex parts in the automotive and aerospace industries. Figure 9 shows some examples of produced and repaired parts for aerospace applications.

One important advantage of the DLD process in comparison to other AM technologies is the higher building rates that can be achieved [63]. Another important advantage of the DLD process is that the technology not only can be deployed to produce parts but also can be used to deposit materials selectively on existing parts and uneven surfaces and thus creating some complex geometries/structures or repair
Fig. 6 Some typical defects in LPBF metallic parts: disconnection from the substrate due to residual stresses in SLM manufactured parts [52]

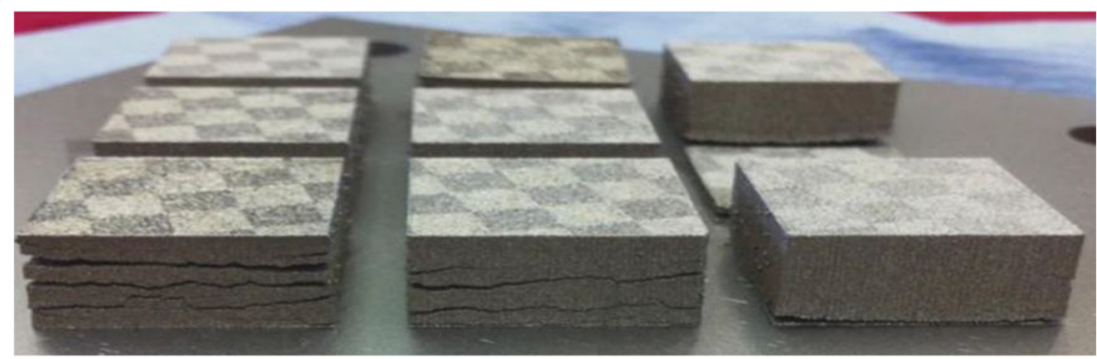




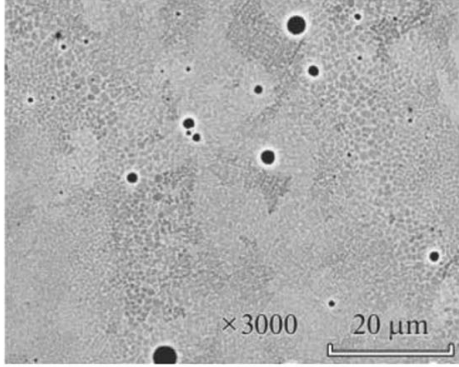

(a)

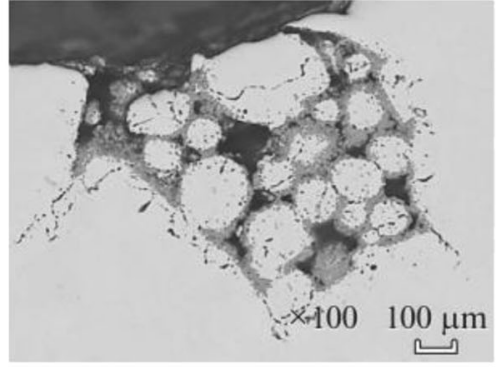

(b)

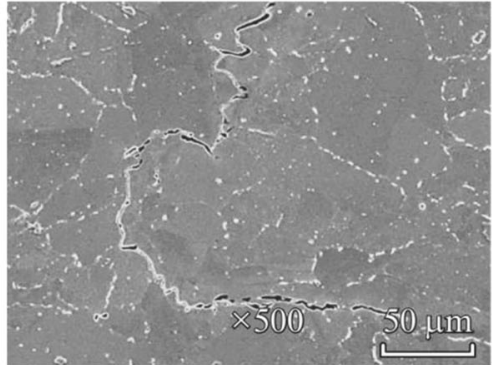

(c)

Fig. 7 More defects in metal components produced by SLM. a Gas pores. b Lack of fusion between powder granules. c Micro- and macrocracks [53]. The figures are reused under the Creative Commons CC-BY licence

damaged or worn out features of high-value components. Thus, the DLD technology offers significant flexibility in manufacturing and repairing metal components. Furthermore, DLD enables the use of different powder materials in the same process, sometimes even simultaneously, and thus producing parts from functionally graded materials or customised alloys [18].

However, as with the LPBF process, the DLD technology has some disadvantages and limitations, too, that have to be considered. Some of them are common across metal AM technologies and have already been mentioned in regard to the LPBF process. In particular, the achievable dimensional accuracy, surface roughness, "staircase effects", porosity and residual stresses are limitations that also apply to the DLD process. In addition, the DLD process is not usually integrated into chambers with a controlled environment; therefore, a shielding inert gas is usually used to surround the melt pool and thus minimising the powder oxidation, as shown in Fig. 8.
However, depending on the gas shielding performance of the DLD heads and the processed material, this might not be sufficient to prevent any oxidation during the deposition and thus affecting negatively the integrity of the part. Furthermore, the DLD parts show a lower hardness, higher ductility and higher toughness in comparison with the LPBF ones [64]. Figure 10 shows examples of defects that can be found in DLD parts.

\subsubsection{Limitations of powder-based laser additive manufacturing for producing metal parts}

Laser-based AM processes, i.e. LPBF and DLD, for producing metal parts by consolidating metallic powders are powerful methods to produce complex structures that were not achievable with conventional manufacturing technologies. Additionally, the amount of material required for their manufacture is much lower and thus a higher resource efficiency can be achieved. However, laser-based AM technologies have
Fig. 8 Schematic diagram of powder-based DLD process

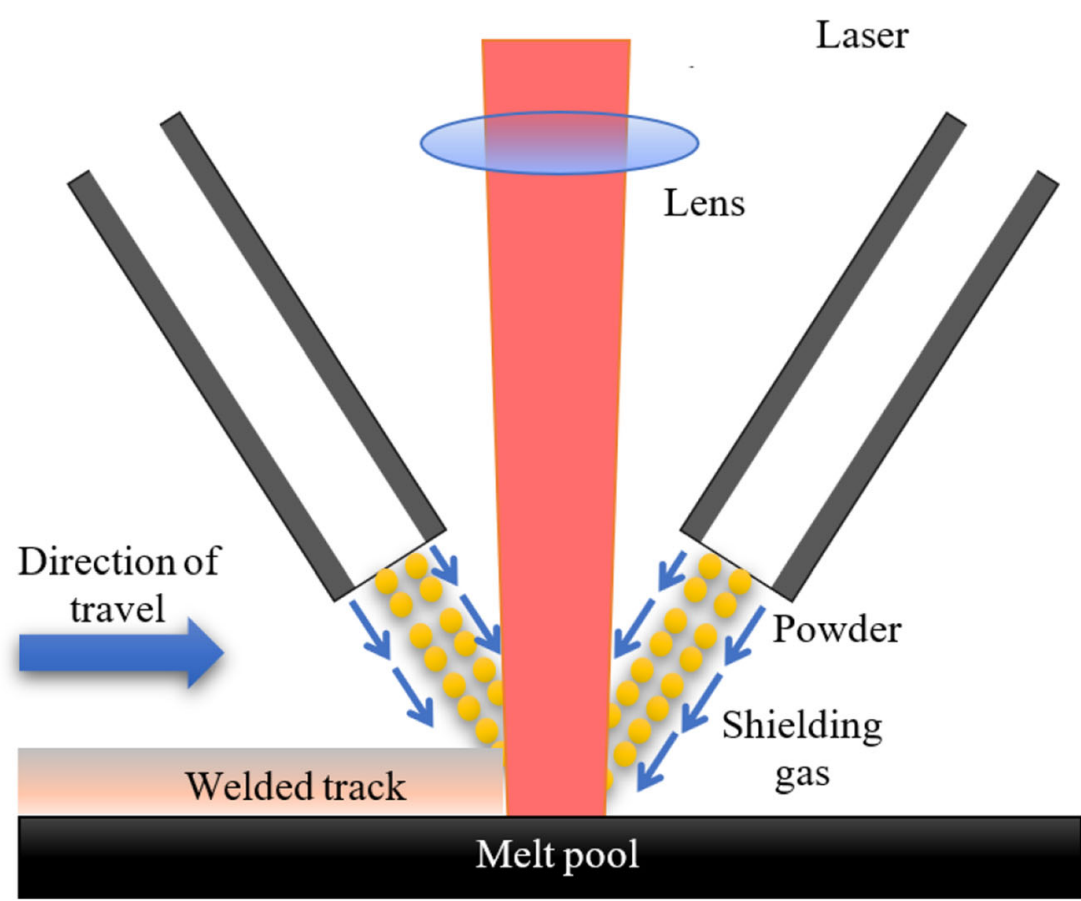




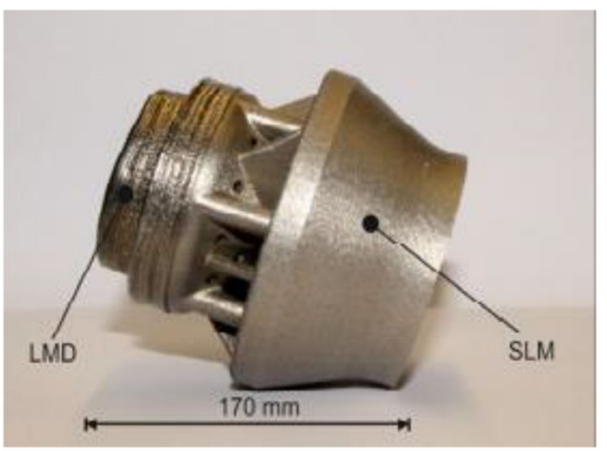

(a)

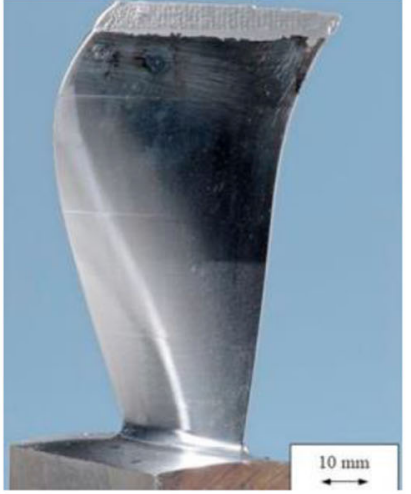

(b)

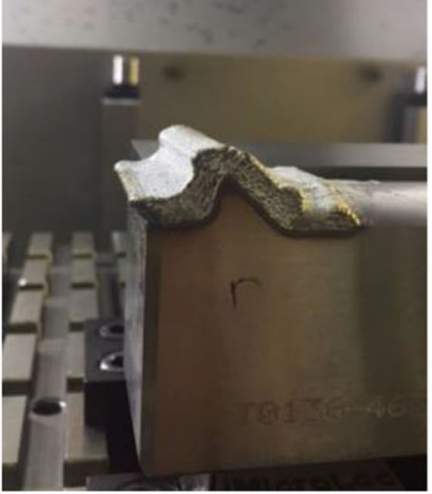

(c)

Fig. 9 Industrial applications of the DLD process. a Rebuilt burner [60]. b Blade tip repair [61]. c Die insert repair [62]

limitations, too, that have to be addressed in order to broaden their use by industry.

The low surface integrity and accuracy together with the porosity of the produced metal parts are some of the main limitations of these AM technologies [67, 68]. These shortcomings are even of a higher concern when manufacturing high-value and safety critical parts that have to meet stringent industrial requirements. Khorasani et al. [69] concluded that significant post-processing was required when parts with curved geometries were produced with the LPBF process in order to improve their surface roughness. It was also highlighted that some of the part surfaces could be distorted and cracks and lines could appear due to powder variations during the LPBF process. Figure 11 shows examples of issues and defects of parts manufactured by laser-based additive manufacturing processes.

Figure $11 \mathrm{a}, \mathrm{b}$ and $\mathrm{c}$ show examples of crack formation, unmelted and stacked powder and surface roughness in LPBF parts. Additionally, Fig. 11d shows the deformation generated by the accumulation of residual stresses. Concretely, as shown in the figure, a gap is created between two components due to the distortion. Finally, Fig. 11e shows another example of part deformation due to thermal distortion. The area highlighted in red, which was intended to be flat, presents an overhang tilt generated by this distortion.

In addition to the geometrical quality of parts, consistent mechanical properties and microstructure are also required for many applications while LPBF and DLD parts usually show a
Fig. 10 Common defects and surface quality of DLD metallic parts. a Crack formation during the deposition [65]. b Porosity [66]
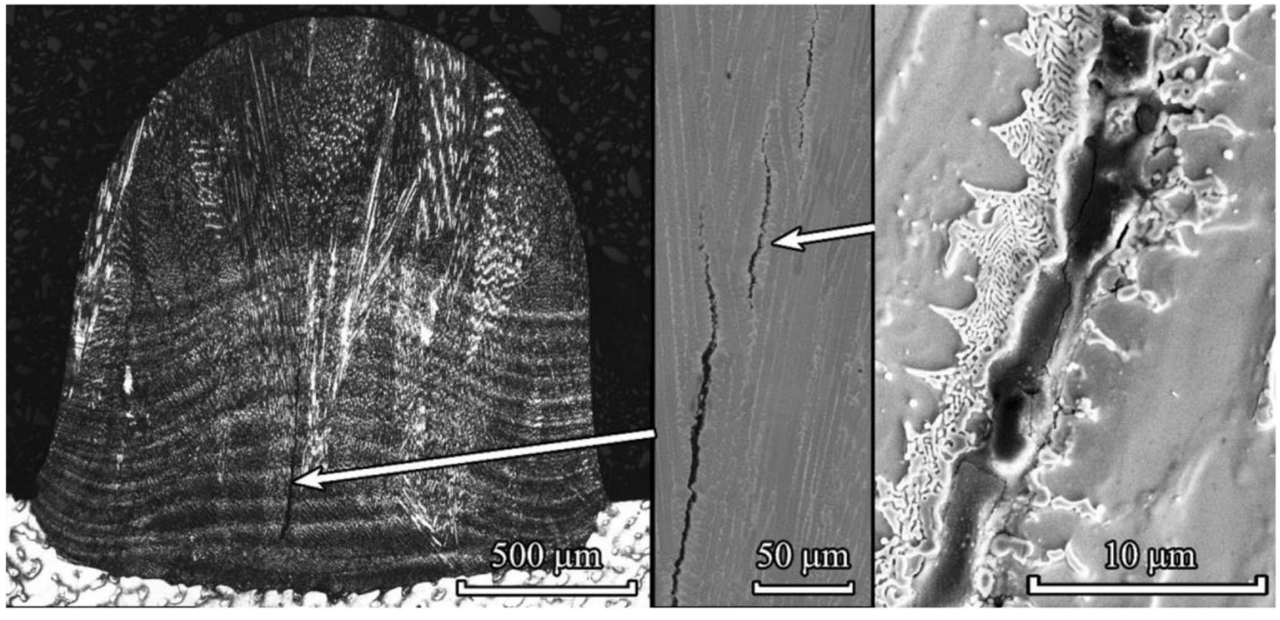

(a)

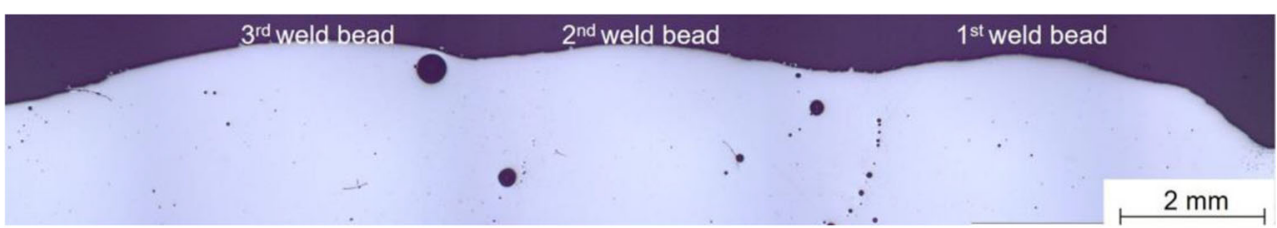

(b) 


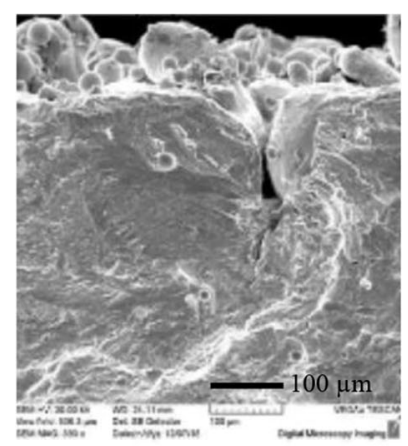

(a)

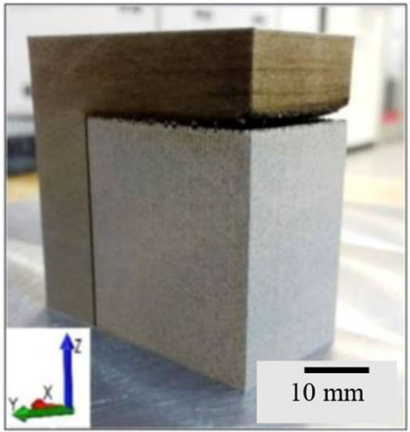

(d)

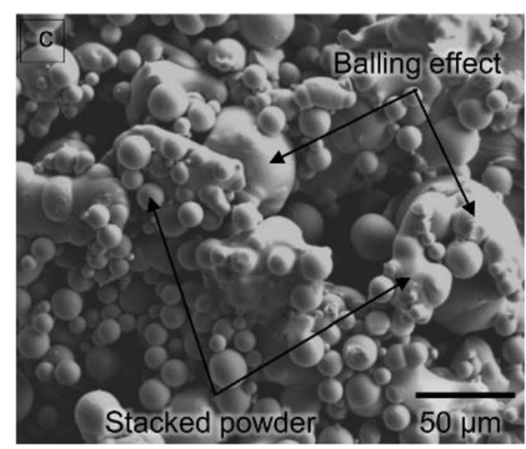

(b)

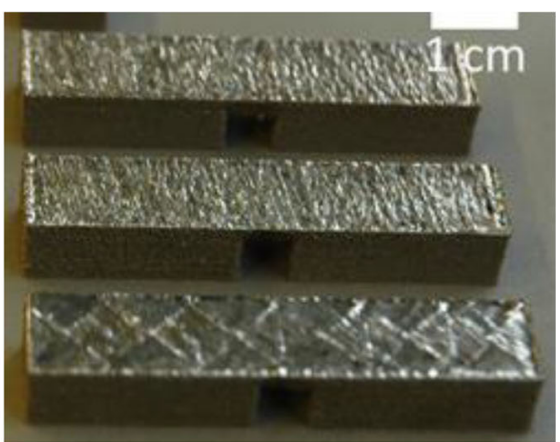

(c)

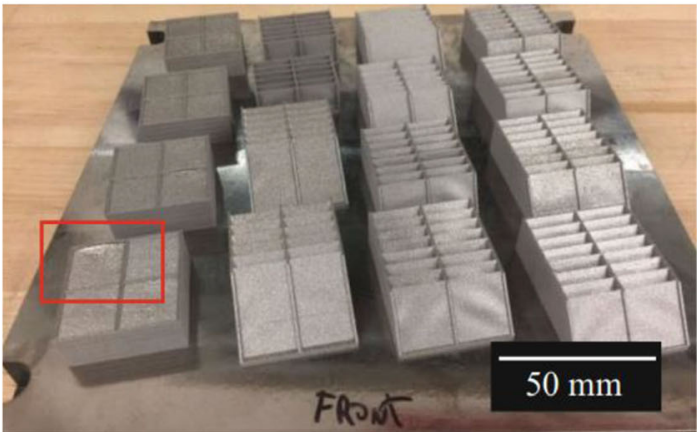

(e)

Fig. 11 Main limitations of additive manufacturing. a Crack formation [70]. b Unmelted and stacked powder [71]. c Surface roughness depending on the scanning strategy [72]. d Part deformations [73]. e Overhang tilt due to thermal distortion (highlighted in red) [74]

significant anisotropy $[67,75]$. Another factor that has a significant impact on part properties is the residual stresses generated not only in the produced parts but also in the building substrates. As it was already discussed, residual stresses are the result of the thermal gradient that occurs during the AM process and can reduce the fatigue life of produced parts. Also, they can lead to part deformations and distortions that can cause the built structures to separate from the base or substrates and the formation of cracks and delamination between the deposited layers $[45,76]$.

With regard to part designs, DLD and LPBF are generally considered to provide designers with significant freedom to explore a much bigger if not unlimited design space. However, as with all manufacturing technologies, they have limitations regarding the complexity of part geometries that can be produced reliably and required repeatability. In particular, the build size in LPBF is limited by the dimensions of the building substrate and the additive system [77-79]. In 2018, Arregui et al. [80] analysed the minimum slope that can be achieved on inclined walls by DLD and concluded that for small slope angles, the laser head should be inclined so that the deposition to be carried out with a head normal to the substrate to avoid geometrical distortions. Additionally, support structures are usually necessary when DLD or LPBF is used to manufacture certain complex geometries, e.g. overhangs, undercuts and part assemblies with moving components, that are then removed using a post-processing operation. However, the removal of such support structures by machining can become difficult and even impossible [78, 81, 82]. As a consequence, a re-design of parts can be required to eliminate or minimise the need for support structures.

The available materials for the DLD and LPBF processes are limited, and therefore, significant research efforts are focused on the development of new alloys and also on the creation of dedicated material databases and standards $[68,75$, 83, 84]. Additionally, there is a significant research interest in the development of process models that can predict quality, dimensional accuracy, and mechanical properties of the produced AM parts.

Finally, when compared to conventional manufacturing methods for producing metal parts, the LPBF and DLD processes present the following shortcomings:

- High cost of the LPBF and DLD machines and the materials for them

- Relatively low production rates are important shortcomings [67, 85].

- Powder recyclability could be a solution to high material costs in PBF processes. However, the powder morphology might be affected when a recycled material is used, and this can impact the part density, hardness and mechanical properties [86]. Furthermore, the recycling process should 
ensure that any partially melted or highly heated particles are separated from those that will be reused [87-89].

- Depending on the metallic powder used in the AM processes, chemical reactions may occur between the powder and contaminants in the building environment, such as oxygen, leading to changes in the chemical composition of the powder [90].

- Taking into account the small size of powder particles in both laser-based AM processes, i.e. 10-20 $\mu \mathrm{m}$ in LPBF and 50-150 $\mu \mathrm{m}$ in DLD, health and safety issues have to be considered, too, when handling metallic powders [91].

Table 1 provides a summary of the advantages and limitations that have been reported for the LPBF and DLD technologies.

It can be stated that achievable accuracy, surface integrity, porosity, relatively poor mechanical and microstructural properties, geometric and material limitations, need for support structures, the high production cost and low production rates are the most challenging issues associated with laser-based AM for building parts from metallic powders. Many of them can be addressed with the use of post-processing operations, such as machining, heat treatments and surface finishing. In the next section, the need for post-processing operations that can be fully integrated with powder-based laser AM processes is discussed.

\section{The need for hybrid}

As it was already discussed, powder-based laser AM technologies have several shortcomings that represent a significant barrier for their broader use for producing functional parts.
Therefore, almost all AM parts need some post-processing, e.g. machining, heat treatment or surface treatment [93-95]. Hybrid AM, as an integration of AM processes with some post-processing technologies, aim to combine their capabilities synergistically and thus producing functional components with complex geometries, enhanced mechanical properties and improved surface integrity. Machining operations, e.g. turning and milling, heat treatments, e.g. conventional and laser heat treatments, and surface treatments, e.g. shot peening and laser shot peening, are among the most common postprocessing operations used in hybrid AM.

Figure 12 shows the advantages of hybrid AM as a combination of additive and $\mathrm{CNC}$ machining processes and thus achieving improvements in surface integrity and accuracy. Hybrid AM is also aimed to enable complex shape generation and reduce the waste material and in some cases the lead-time that are associated with machining processes.

In addition to the external defects of AM parts that can be removed by machining, porosity, microstructural defects and residual stresses are other major concerns as they affect the mechanical properties of the parts. Heat and surface treatments have shown to enhance the mechanical properties of AM parts and also to reduce the porosity and improve their microstructural characteristics. Additionally, some of these treatments have shown to reduce the tensile residual stresses of AM parts; hence, their fatigue behaviour is also improved [96-104].

As it was already discussed, the main advantage of AM technologies when compared to conventional manufacturing technologies, such as machining and forging, is that they enable the manufacture of much more complex parts that can incorporate internal cavities while the waste material is drastically reduced [105]. However, these advantages are at the

Table 1 Advantages and limitations of powder-based laser AM technologies

\begin{tabular}{|c|c|c|c|c|}
\hline AM process & Technology & Advantages & Limitations & Ref \\
\hline Powder bed fusion & LPBF & $\begin{array}{l}\text { - Higher accuracy and fine details } \\
\text { - Fully dense parts } \\
\text { - High specific strength and stiffness } \\
\text { - Powder recycling }\end{array}$ & $\begin{array}{l}\text { - Powder handling } \\
\text { - Need for support structures } \\
\text { - High residual stresses } \\
\text { - Microstructural and mechanical anisotropy } \\
\text { - Size limitation } \\
\text { - Low productivity } \\
\text { - Limited process modelling and control } \\
\text { - Post-processing required } \\
\text { - Health and safety issues }\end{array}$ & $\begin{array}{l}{[87-89]} \\
{[78,84,92]} \\
{[45]} \\
{[75]} \\
{[77-79]} \\
{[67,85]} \\
{[75,83]} \\
{[69,78]} \\
{[91]}\end{array}$ \\
\hline Direct energy deposition & DLD & $\begin{array}{l}\text { - Repair of damaged or worn parts } \\
\text { - Flexibility } \\
\text { - Functionally graded material generation } \\
\text { - Alloy development }\end{array}$ & $\begin{array}{l}\text { - Low accuracy } \\
\text { - Rough surface finish } \\
\text { - Porosity of parts } \\
\text { - Residual stresses } \\
\text { - Limitations in printing complex shapes } \\
\text { - Process modelling and control } \\
\text { - Post-processing required } \\
\text { - Health and safety issues }\end{array}$ & $\begin{array}{l}{[67,68]} \\
{[67,68]} \\
{[67,68]} \\
{[76]} \\
{[80]} \\
{[75]} \\
{[78,92]} \\
{[91]}\end{array}$ \\
\hline
\end{tabular}


Fig. 12 Advantages in combining $\mathrm{AM}$ and machining processes

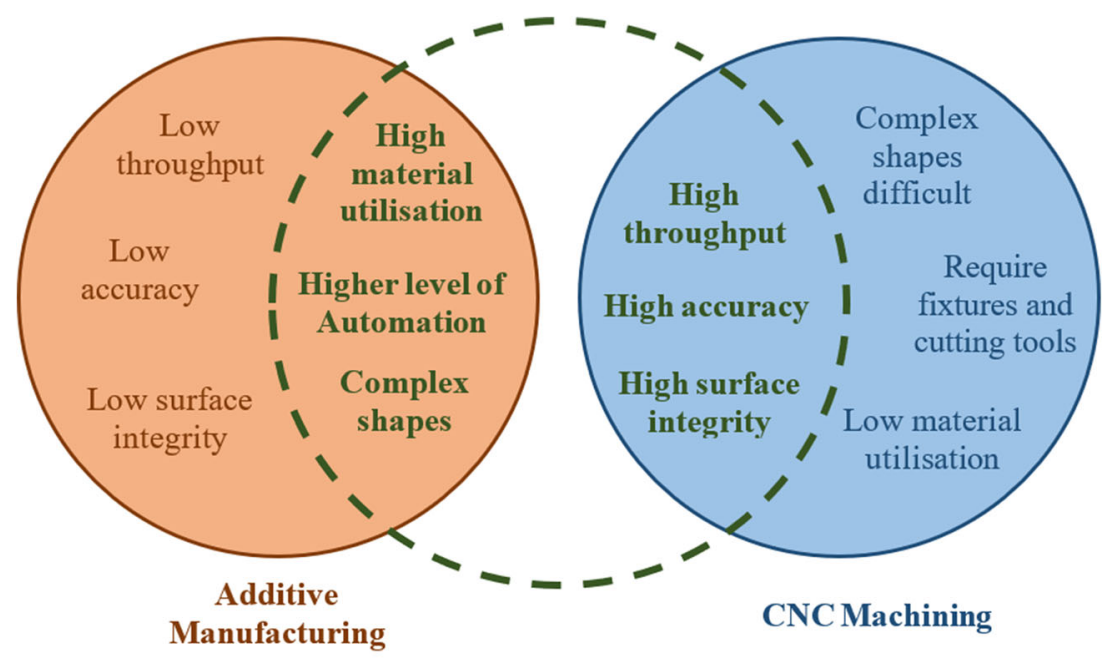

HYBRID MANUFACTURING

expense of some inherent limitations associated with the layer-by-layer manufacture [106].

As an example of the benefits that hybrid AM can offer by combining powder-based laser AM with postprocessing operations, surface roughness values achievable with machining and polishing operations are compared with those achievable with the LPBF and DLD technologies in Table 2. Additionally, the surface roughness values of parts manufactured using Hybrid AM are also included.

As shown in the table, surface roughness values achievable with the LPBF and DLD processes are in the ranges between 5-40 and 30-110 $\mu \mathrm{m}$, respectively, while in turning or milling, the values decrease to $1-8 \mu \mathrm{m}$ and $1.5-10 \mu \mathrm{m}$, respectively. It is also shown that when post-processing AM parts by employing machining or heat and surface treatments, the roughness is considerably decreased, and values can be reached that are similar to those achievable with conventional manufacturing operations. In addition to surface roughness, dimensional accuracy of AM parts can also be improved and sections with excessive material due to distortions occurring during the AM process can be removed by milling or turning operations. With regard to heat and surface treatments, it is reported that they can improve part quality, reduce surface roughness and relieve residuals stresses that in turn improves the fatigue life and microstructure of the AM parts [112-121].

It is also worth reiterating that hybrid AM can reduce material waste and lead time and thus reducing the manufacturing costs, too. Regarding the reduction in material waste, by using additive manufacturing as the primary process, near-net-shape parts are generated. Therefore, the amount of material that is removed later in machining operations is much lower than that in the conventional machining processes. This is especially advantageous for the manufacturing of great components employed in the casting and moulding industries. Additionally, in hybrid AM systems, potential human errors can be minimised and even eliminated as all processing steps can be automated by employing $\mathrm{CAD} / \mathrm{CAM}$ solutions. As a result, functional and end-use parts can be efficiently produced on demand with a minimum lead time.

In the next section, different hybrid AM solutions for producing metal parts are presented.
Table 2 Comparison of roughness values achievable with machining operations, AM technologies and hybrid AM

\begin{tabular}{llll}
\hline Manufacturing process & Technology & Roughness Ra $(\mu \mathrm{m})$ & Ref. \\
\hline Machining & Turning & $1-8$ & {$[107]$} \\
& Milling & $1.5-10$ & {$[107]$} \\
Additive manufacturing & Polishing & $0.2-1$ & {$[107]$} \\
& LPBF & $5-40$ & {$[108]$} \\
Hybrid AM & DLD & $30-110$ & {$[109]$} \\
& DLD + turning & $1.45-1.90$ & {$[110]$} \\
& LPBF + shot peening & 16 & {$[73]$} \\
& DLD + laser re-melting & 1.5 & {$[109]$} \\
& DLD + laser polishing & 2 & {$[111]$} \\
\hline
\end{tabular}




\section{Hybrid AM solutions}

Research on combining the capabilities of powder-based laser AM processes with some post-processing operations is reviewed. In Table 3, a summary of the hybrid AM solutions that are analysed and discussed in this section is presented. Different process combinations are reviewed, and their main advantages and limitation are highlighted.

\subsection{Hybrid additive/machining solutions}

A review of hybrid AM solutions that combine the capabilities of powder-based laser AM technologies with post-processing machining processes is presented in this section. In particular, in such hybrid solutions, near-net-shape components are first produced by LPBF or DLD technologies and then they are post-processed by employing machining operations, e.g. turning or milling. The machining operations can be conducted once the AM process is completed, as a finishing process, or can be alternatively applied after the consolidation of a given number of powder layers.

Figure 13 extracted from the work by Foster et al. [62] shows an example of the improvement that can be obtained in the surface finish of additively manufactured components by post-processing through machining operations.

Different approaches for combining seamlessly and synergistically the capabilities of powder-based laser AM technologies with post-processing machining processes have been implemented. In 2007, Liou et al. [77] reported a hybrid solution that integrates DLD and machining processes into a 5axis single setup for producing metallic parts. First, the authors studied the necessity for support structures during the powder deposition process and thus determining whether the
DLD process could be conducted without them by changing the part orientation. Then, based on the findings of this investigation, an approach for partitioning part models into subparts was proposed that eliminated the need for support structures when different processing positions in a 5 -axis machine were used for each subpart. The pre-processing of each subpart model, i.e. its slicing, was carried out separately and thus using optimum DLD conditions for processing the subparts.

According to Jones et al. [135], the productivity of AM technologies is typically one order of magnitude lower than that of CNC machining. Therefore, a hybrid AM solution was proposed that combines the capabilities of DLD and CNC machining processes into a single multi-axis setup and thus improving both surface integrity and productivity. In this work, the tool changer solution was proposed, too (see Fig. 14) that allowed a laser cladding head and different cutting tools to be used in the same system.

The machining operation can be applied not only for finishing metal AM parts but also in alternation to the deposition of layers in hybrid AM solutions. In this way, Karunakaran et al. [7] reported a hybrid AM system in which near-net-shape structures were first produced by using a DLD head, i.e. a welding head, mounted on a table and subsequently machined to net shape. As the deposition was carried out in the form of weld beads, the surface of the deposited layer was uneven due to the scallops and the developed thin oxide layer. Thus, such uneven deposition of layers can have a cumulative effect on the accuracy of the component in the $\mathrm{Z}$ direction and therefore this shortcoming was addressed by face milling each layer to the required slice thickness. So, each subsequent weld-deposition was conducted on a pre-machined surface and thus having good quality welds and build metal parts consistently. A similar hybrid AM solution was proposed by

Table 3 Summary of hybrid manufacturing processes

\begin{tabular}{|c|c|c|c|c|c|}
\hline $\begin{array}{l}\text { Hybrid } \\
\text { manufacturing }\end{array}$ & $\begin{array}{l}\mathrm{AM} \\
\text { technology }\end{array}$ & Post-processing & Advantages & Limitations and challenges & Ref. \\
\hline \multirow{2}{*}{$\begin{array}{l}\text { Additive } \\
\text { manufacturing }+ \\
\text { machining }\end{array}$} & LPBF & Machining & $\begin{array}{l}\text { Complex geometries and good } \\
\text { surface finish }\end{array}$ & \multirow{2}{*}{$\begin{array}{l}\text { Needs part inspections, software integration, } \\
\text { parameter optimisation, oxidation (out of } \\
\text { chamber AM). Undercuts cannot be } \\
\text { machined. }\end{array}$} & {$[77,79]$} \\
\hline & DLD & Machining & $\begin{array}{l}\text { Productivity gains and good surface } \\
\text { finish }\end{array}$ & & $\begin{array}{c}{[10,122,} \\
123]\end{array}$ \\
\hline \multirow[t]{2}{*}{$\begin{array}{l}\text { Additive } \\
\text { manufacturing }+ \\
\text { heat treatment }\end{array}$} & $\mathrm{LPBF}$ & Laser re-melting & $\begin{array}{l}\text { Improved microstructure, reduced } \\
\text { residual stresses and surface } \\
\text { roughness and enhanced surface } \\
\text { properties }\end{array}$ & Needs parameters optimisation. & {$[124-131]$} \\
\hline & DLD & Laser re-melting & $\begin{array}{l}\text { Smooth surfaces and isotropic } \\
\text { topographies }\end{array}$ & Needs parameters optimisation & [132] \\
\hline \multirow{3}{*}{$\begin{array}{l}\text { Additive } \\
\text { manufacturing }+ \\
\text { surface treatment }\end{array}$} & LPBF & Laser polishing & Reduced surface roughness & $\begin{array}{l}\text { Process optimisation is required to avoid } \\
\text { oxidation }\end{array}$ & [133] \\
\hline & DLD & Laser polishing & Reduced surface roughness & Results are highly dependent on laser energy & [111] \\
\hline & DLD & Peening & $\begin{array}{l}\text { Refined microstructure and } \\
\text { beneficial compressive residual } \\
\text { stresses }\end{array}$ & Integration of processes in the same machine. & [134] \\
\hline
\end{tabular}


Fig. 13 Surface finish of samples in (a) as deposited and after machining states [62]

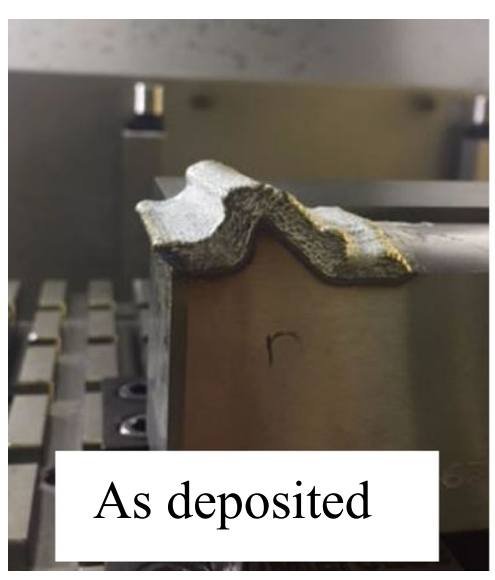

other researchers but it was combining LPBF with precision milling in a single setup [79]. In particular, the parts were manufactured layer by layer by conducting LPBF and machining steps sequentially onto a substrate clamped on a worktable as shown in Fig. 15. By employing this hybrid AM/ machining process, complex internal structures, such as cooling channels, were produced. The manufacture of $18 \mathrm{Ni}$ steel parts was reported, and their microstructure and hardness were analysed and compared with those achieved on parts produced by a standalone LPBF system and other methods. It was reported that the hybrid samples showed density higher than $99 \%$, fine microstructure and higher hardness than the result obtained on parts fabricated using the standalone LPBF process.

The development of a hybrid multi-tasking machine tool was reported where a DLD head was integrated with turning and milling capabilities into a hybrid solution for reducing the manufacturing time and the total in-process time [136]. This hybrid manufacturing platform was implemented into a commercially available machine tool, Integrex i-400 AM, to address the specific requirements in the small-lot production of difficult-to-cut high-hardness materials for applications in aerospace, energy, medical device and tool-making industrial

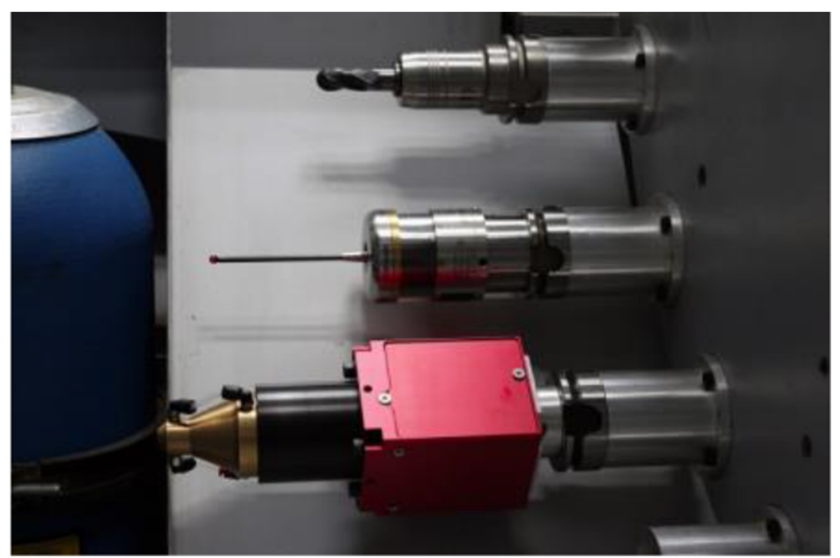

Fig. 14 Image of the cladding head, touch probe, and end mill co-existing in the tool changer [135] sector. Figure 16 depicts an application of this hybrid AM solution for producing a bi-metal part with a stainless steel substrate and deposited Inconel 718 on it.

Another approach for creating hybrid AM solutions is the integration of AM technologies with pre-processing and postprocessing processes into multi-setup manufacturing platforms through the use of common work holding systems. The design and implementation of such modular work holding system were reported for integrating the LPBF process into AM enable process chains [122].

It is important to stress on differences between single- and multi-setup hybrid AM solutions, especially former execute AM and post-processing operations in one machine tool that later addresses fixturing and position issues in moving the components along a given AM enabled process chain. The multi-setup hybrid AM enabled manufacturing platforms to address some of the limitations of single setup ones. In particular, the AM and machining modules integrated into multisetup solutions can be optimised independently to address the specific performance requirements of an individual process rather than the requirements of all integrated manufacturing processes into a single setup [97]. So, the fundamental differences in the physical characteristics of integrated processes would not increase the engineering complexity of such multi-setup manufacturing solutions unnecessarily and therefore their overall cost would not increase considerably, compared to the single setup systems. Other important advantages of the process chain approach in combining AM capabilities with other processes is that it can deliver much higher productivity due to the parallel utilisation of the integrated operations and also because it provides flexibility to synchronise the throughputs of each manufacturing module [137].

The modular work holding system reported in [122] was later employed by Badhuri et al. [82] to investigate the surface integrity, microstructure and mechanical properties of hybrid AM aluminium parts produced by employing LPBF followed by some machining operations. In another research, the same work holding system was deployed to build LPBF structures on top of metal injection moulded (MIM) preforms and thus 
Fig. 15 Schematic description of the hybrid $\mathrm{LPBF} /$ machining process [79]. The figures are reused under the Creative Commons CC-BY licence

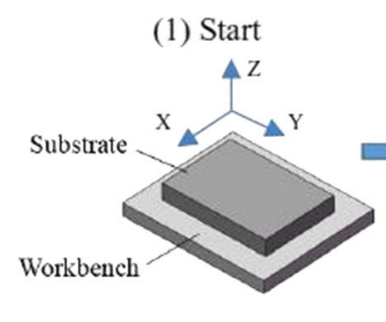

(2) Additive process

(3) Milling

(4) Additive process

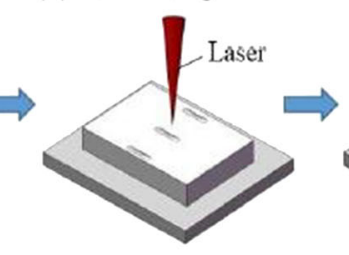

(6) Additive process

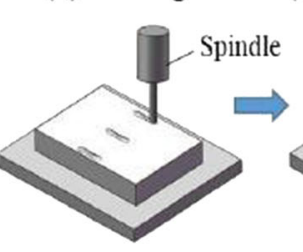

(7) Milling

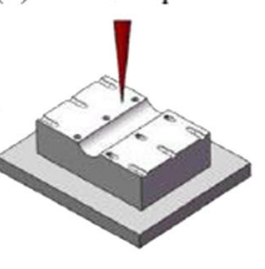

(8) Finish

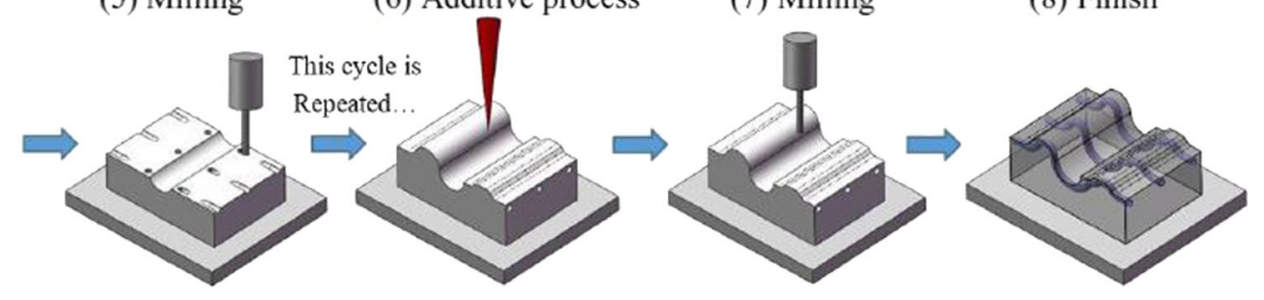

producing small series of hybrid 316L stainless steel components [138]. The mechanical properties and interfaces of such hybrid MIM/LPBF components were investigated and it was reported that they were similar and even better than those of monolithic MIM parts while conforming fully to the ASTM standards for 316L stainless steel parts.

A similar multi-setup approach was employed by Boivie et al. [123] to combine the LPBF process with 5axis milling and thus producing injection moulding tools. In particular, the implemented hybrid AM solution enabled the manufacture of conformal cooling channels in complex cavities that led to the production of higher quality mouldings and also allowed the injection moulding cycle time to be reduced, significantly.

\subsection{Hybrid additive/surface treatment solutions}

The hybrid AM/surface treatment solutions are similar to hybrid $\mathrm{AM} /$ machining ones as the processes are carried out sequentially either on single or multi-setups. In particular, in the latter, near-net-shape components are produced employing an AM process and then they are treated to improve their microstructure and mechanical properties and also to reduce the residual stresses. While in the former, treatment can be applied in the same AM setup after the deposition of layers [139, 140]. In this review, laser re-melting (LR), laser peening and laser polishing are considered as surface treatments solutions to improve the properties of AM components.

Laser re-melting (LR) is a process that has attracted a growing interest from researchers and industry. LR has shown to decrease porosity and improve the microstructure of the AM parts (see Fig. 17).

Huang et al. [125] defined "laser re-melting" as scanning strategies that have more than one laser beam pass for each LPBF layer. The second and any further beam passes aim to increase the material densification and also to improve surface integrity and microstructure. A similar approach was applied by Lamikiz et al. [126], however, this time sequentially as a hybrid multi-setup solution. In particular, a laser beam was employed to melt a microscopic layer on the surfaces of LPBF parts that after its re-solidification made the LPBF surfaces smoother. An $80 \%$ reduction of the average surface roughness was achieved by applying this laser treatment method. More recently, Yasa et al. [127] studied the influence of different laser processing parameters, i.e. scan speed, scan spacing and number of re-melting scans, on porosity, surface roughness and microhardness of AISI 316L stainless steel and Ti6Al4V parts produced by the LPBF process. In all experiments, the use of re-melting scans improved surface integrity and properties of produced parts. Considering the parameter range employed in their work, authors observed that higher remelting scan speed combined with low laser power showed low porosity values. Additionally, in low-energy input tests, no relevant change in porosity was observed when increasing from one to three re-melting scans. However, as the energy input was increased and, at the same time, the number of re-melting scans was also increased, the porosity increased significantly. In another research, the same authors investigated the effect of laser re-melting when applied only to the last layer of LPBF AISI 316L parts and again a $90 \%$ improvement of the surface roughness was reported [128]. Yang et al. [129] studied the changes in microhardness and microstructure after laser re-melting of LPBF samples, too. The results showed that laser remelting had refined the material microstructure, i.e. had reduced the grain sizes, and also homogenised the material composition that improved microhardness of the treated samples. Wei et al. [130] carried out a study on the influence of the number of re-melting scans on porosity, roughness and residual stresses. It was reported that the scan number did not affect porosity and roughness. However, the residual stresses increased when one re-melting scan was used and then decreased after two or more re-melting scans. 
Fig. 16 Application example of the hybrid multi-tasking machine tool, Mazak INTEGREX i-400 AM [136]. The figures are reused under the Creative Commons CCBY licence
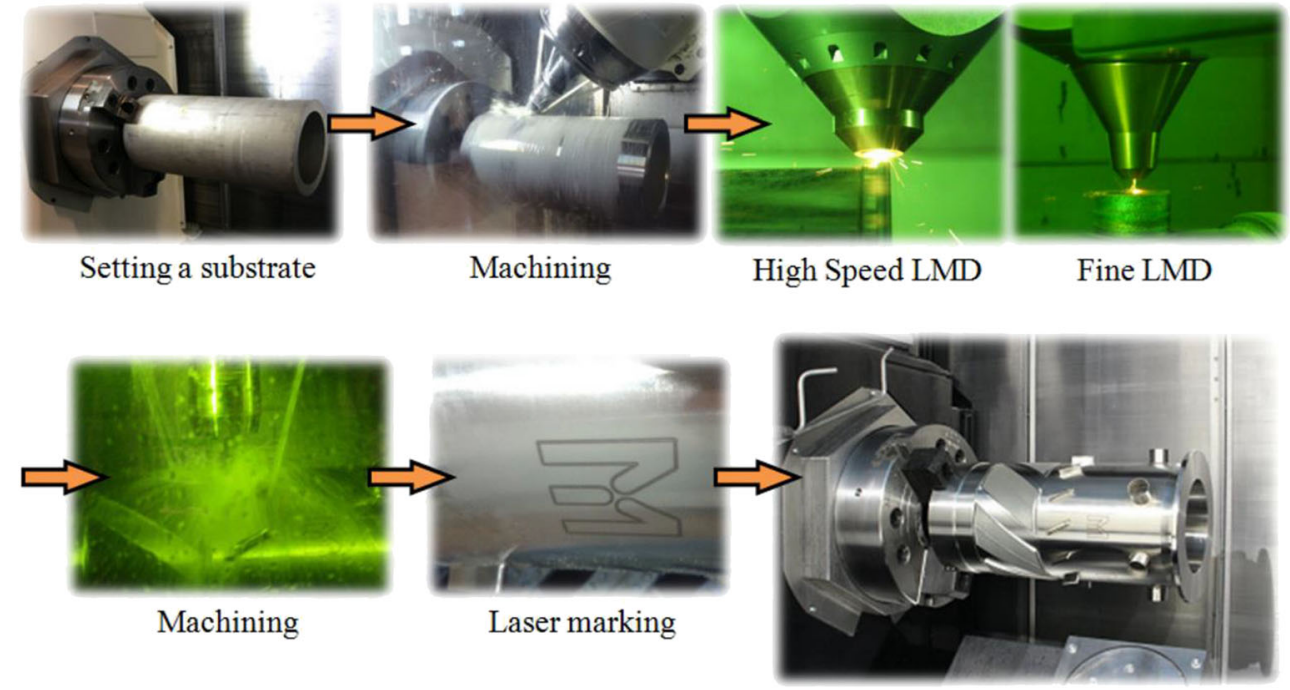

In another research, Yu et al. [131] studied the influence of using different scanning directions during the LPBF and remelting processes, on roughness and porosities of produced parts. It was reported that the scan strategies investigated in this research led to the same roughness decreasing trend. However, the use of different scan directions had affected the porosity of produced LPBF parts.

Laser re-melting has also been employed for post-processing DLD parts. Bruzzo et al. [132] investigated the surface integrity improvements of thin-walled parts after laser re-melting. It was reported that, when suitable re-melting parameters were employed, a smooth surface with isotropic topographies was obtained. Recently, Roehling et al. [142] investigated in situ laser diode annealing integrated into a LPBF system for reducing the resulting residual stresses. It was reported that such integrated heat treatment can reduce the resulting residual stresses in 316L stainless steel parts by $90 \%$ without grain growth or recrystallisation, and with only minor changes to the solidification structure.

Peening (also known as shot penning) is another hybrid $\mathrm{AM} /$ surface treatment approach that can be used to improve the surface finish and mechanical behaviour of metallic AM parts (see Fig. 18b).

In particular, it has shown to harden and strengthen the surfaces of AM parts by generating compressive residual stresses. As a consequence, favourable mechanical properties are created on treated surfaces that can increase their fatigue life (see Fig. 19) and wear resistance and thus delaying the initiation and propagation of cracks. In the work by Hackel et al. [100], authors show that laser peening can improve the fatigue lifetime of components more than 20 times comparing to that of the untreated part.

Wang et al. [134] studied the effects of in situ ultrasonic impact peening on Inconel 718 parts produced with the DLD technology. It was reported that the ultrasonic impact peening enabled the generation of high-quality metal parts with refined microstructure on their treated surfaces. In addition, the residual stresses of the treated surface were reduced by generating beneficial compressive stresses.

Another surface treatment process that can be used to reduce the surface roughness of AM metal parts is laser polishing (see Fig. 18c). Similar to laser re-melting, this post-processing technology melts the external surface asperities of the AM part and thus improves surface integrity. Dadbakhsh et al [111] reported that the surface roughness of DLD Inconel 718 samples was significantly improved after a laser polishing scan with the laser integrated into the DLD head, especially roughness values decreased down to approximately $2 \mu \mathrm{m}$. However, it was noted that the results were highly dependent on the applied laser power during the polishing scans.

\section{Commercial hybrid manufacturing systems}

Table 4 lists the commercially available hybrid systems that gives a general overview of the current status with the take-up of this technology by industry and also their general technical specifications for comparison purposes [144].

In addition to the hybrid machine manufacturers listed in Table 4, there are other companies that have developed flexible solutions to transform machining centres into hybrid machines capable of combining additive and subtractive technologies. For example, 3D Hybrid [155] has developed wire arc, laser and cold spray deposition heads that can be integrated into CNC machines. Fabrisonic [156] patented an ultrasonic AM print-head that can be integrated into any 3 -axis machining centre to convert it into a hybrid AM solution. Finally, Hybrid Manufacturing Technologies [157] has developed a range of tool heads for inspection, machining and DLD 
Fig. 17 Benefits of LR. a Improvement of surface morphology [120]. b Decrease of part porosity [141]
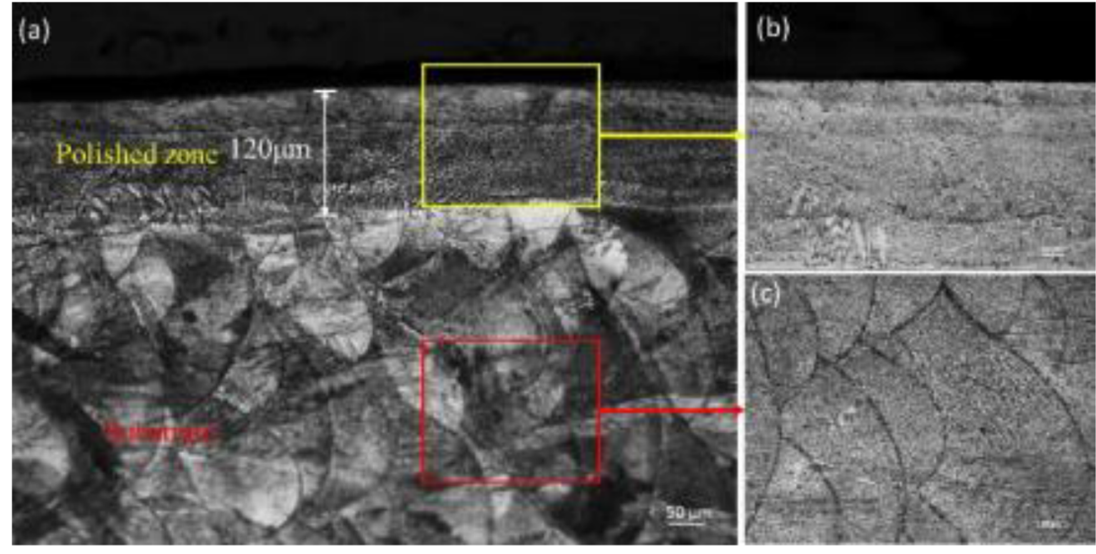

(a)
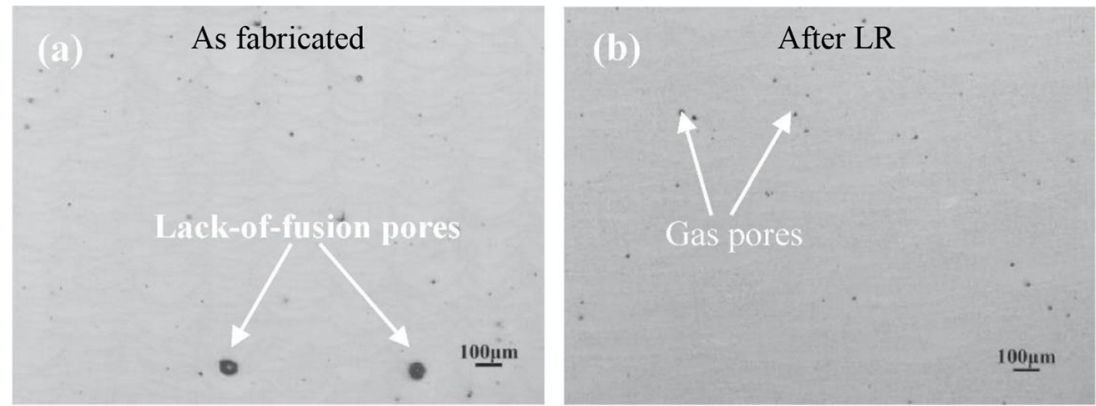

(b)

operations that can be integrated into machining centres and thus creating ad hoc hybrid AM solutions.

It is worth noting that any LPBF or DLD system available currently on the market can also conduct in situ heat or surface treatment operations with their integrated laser sources. As discussed in Section 3.2, these treatments have proved to improve the mechanical properties, microstructure and surface quality of metal AM components. Therefore, any of those systems can be considered potentially as hybrid AM solutions as $\mathrm{AM}$ and the post-processing operations can be carried out in a single setup/machine. In addition, the LPBF machine developed by Additive Industries MetalFAB1 [36] offers an integrated furnace for heat-treatment and therefore can be considered a hybrid AM system.

Apart from the hybrid machined presented above, robotic solutions can also be an alternative for hybrid additive manufacturing systems. These solutions are usually based on DED processes conducted by a robotic arm that is integrated into a machining environment. In fact, robot-assisted additive manufacturing approaches have been widely analysed lately as they offer the possibility to accomplish multi-axis additive manufacturing that can be integrated into different manufacturing environments [158]. As for the hybrid additive manufacturing of metals, Kimpenis et al. [159] presented

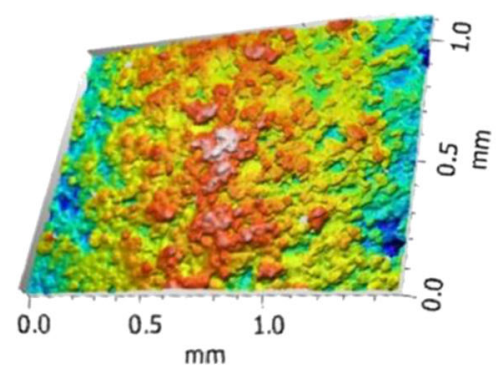

(a)

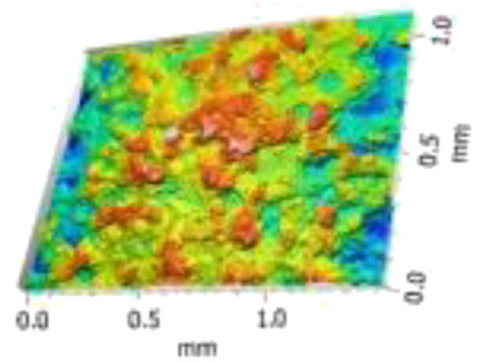

(b)

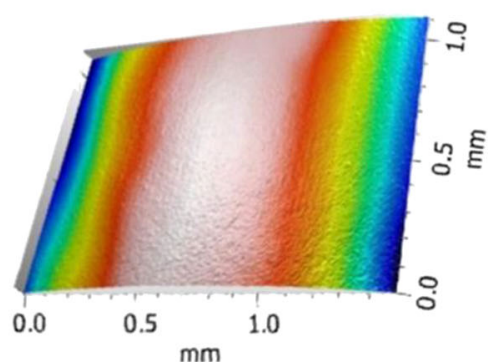

(c)

Fig. 18 Effect of surface treatment on additively manufactured components. a As-fabricated surface topography. b Improvement of surface finish through laser shot peening. c Through laser polishing [143] 
recently the HydraX robot that can be integrated in almost any type of machine and enables to combine multiple processes in a single machine. It is worth noting that almost all components in this robotic arm were generated by AM processes.

\section{Applications of hybrid manufacturing}

Taking advantage of the flexibility offered by AM, hybrid AM solutions enable the manufacture of complex parts with geometries/structures that were previously unachievable. Parts' repair is among the applications that have attracted a significant industrial interest due to the direct economic benefits it can bring in repairing high-value components. The combining AM with post-processing operations in a single or multiple setups enables the repair of damaged or worn parts and thus extending the parts' life span and potentially to avoid the need to replace them with new ones. Additionally, AM processes enable the use of different materials and thus producing multi-material and functionally graded material (FGM) components, which is another very attractive application for hybrid AM solutions.

In this section, a review of the most relevant and highimpact applications of hybrid AM solutions reported in the literature is presented. The feasibility of applying a hybrid AM approach in producing complex geometries, part repairs and the manufacture of FGM parts is discussed. In addition, the advantages and challenges associated with the deployment of this approach for producing parts that can address the specific requirements in different industrial sectors are discussed.

\subsection{Manufacturing of complex end-use geometries}

Hybrid AM solution can combine the capabilities of metal AM technologies with those of different post-processing processes to produce end-use parts. One of the main advantages that AM processes provide is the flexibility and freedom to produce complex geometries with internal cavities that were impossible to achieve with conventional manufacturing processes only. Collision avoidance is one of the biggest issues in generating complex geometries using hybrid AM solutions. In particular, tool accessibility must be maintained over the processed surfaces when post-processing them through various machining operations, and therefore, this issue has to be taken into account during the process design/planning stages. In addition, to minimise any material wastage the machining strategies and part positioning for each post-processing operation should be optimised.

Liou et al. [77] reported a hybrid AM approach for the production of complex parts by integrating a DLD device into a multi-axis CNC machine. The results showed that the need for support structures during the AM process could be avoided by selecting the optimal part positioning and inclination 
angles during the DLD process. A process planning method was proposed in this research for the DLD process that included the following steps: (1) selection of part orientation, (2) part partitioning into subparts for creating them with the same building direction, (3) determining the DLD building sequence and (4) verifying the machinability of built subparts and thus avoiding any collisions during their post-processing. Recently, Chen et al. [160] proposed a new process planning when a hybrid AM approach was utilised. Their research was motivated by the need for proper planning of manufacturing sequences and thus ensuring collision avoidance during both DLD and machining operations. Their research was mainly focused on the application of hybrid AM solutions for producing complex geometries, such as aero-engine blisks and gears, among others. Especially, a model was proposed for simulating the relative in-process movements of workpiece and cutting tools and DLD heads, and thus determining the optimal sequence of tasks in producing complex shapes without collisions.

Sodick [149] machine manufacturer has developed a hybrid AM machine that integrates LPBF and machining operations for the generation of complex end-use parts. Components that can be manufactured with their hybrid OPM series machine are provided in Fig. 20 and Fig. 21. Figure 20 shows samples with internal cavities and complex geometries that were produced by combining LPBF and milling operations, i.e. (a) a sample with a spiral-shaped cooling channel with machined external surfaces, (b) a sample with a high aspect ratio rib; (c) a twisted topologically optimised cage tower with a machined upper surface; and (d) a punch with a narrow high aspect ratio slot.

Figure 21 shows examples of components with internal cooling channels and external complex geometries, i.e. an EV connector, a switch box and a duct shape core, that were not possible to produce with machining operations only, but they were successfully manufactured with the OPM Series machine.

Matsuura [163] has developed a hybrid AM machine that integrates LPBF and machining operations into a single processing setup as shown in Table 4 . Figure 22 shows examples of moulds and components that were manufactured using the Matsuura hybrid AM system.

Finally, Mazak [146] has developed a hybrid AM machine that integrates a DLD head into a multi-tasking machine tool with the technical characteristics given in Table 4. Figure 23 shows product examples that were produced employing this hybrid AM solution.

\subsection{Repair of metallic parts}

The development of metal AM processes has enabled the repair of worn or damaged metallic parts and thus increase their life span and also minimise the need for re-manufacturing. Such capabilities are of special interest in the application areas for high-value components, e.g. in tooling applications where saving in lead time and cost can be made by repairing the damaged dies and moulds [165]. However, taking into account the tight tolerances that are typically required in tool-making, aerospace and automotive industries and also considering the limitations of stand AM systems, hybrid AM solutions have emerged as a viable alternative for repairing parts in these industrial sectors.

As it was already stated, there is significant interest in using hybrid AM solutions for tool repair. Ren et al. [166] reported an alternative approach for die repair that was combining DLD with CNC machining. The repair of most common die damages with such hybrid system was studied, especially dies that were worn out or damaged. The bonding strength of deposited material in such repaired dies was analysed and it was concluded that it was higher when compared with dies
Fig. 19 Fatigue lifetime improvement through laser peening (LP) and shot peening (SP) [100]

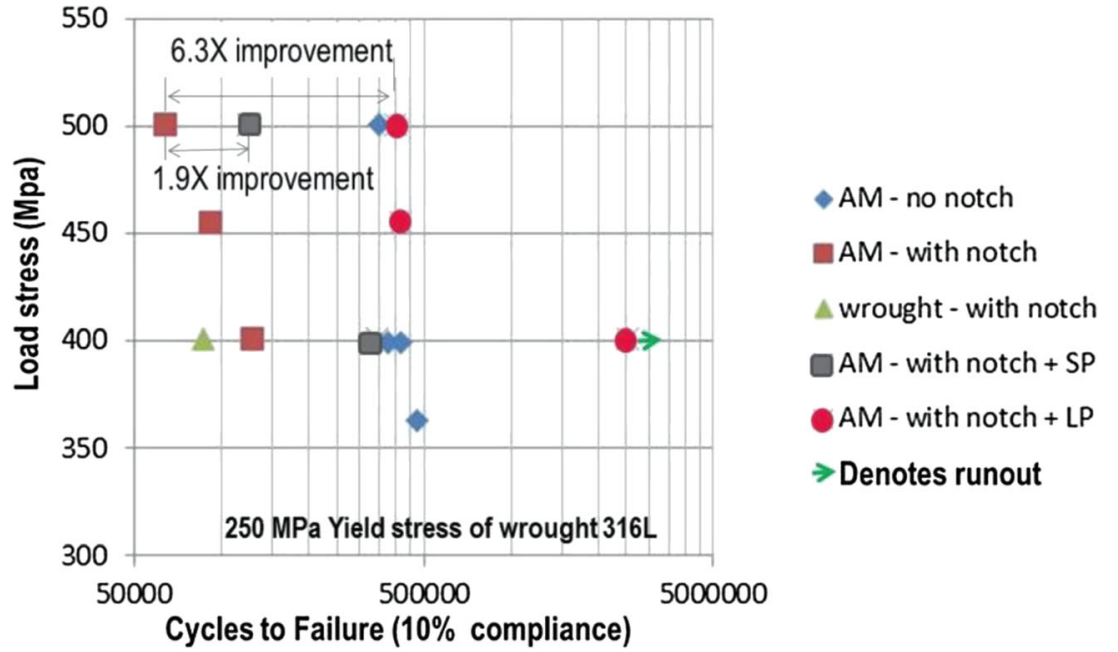


Fig. 20 Hybrid AM parts produced with Sodick's new OPM250L machine that combines LPBF with milling operations [161]

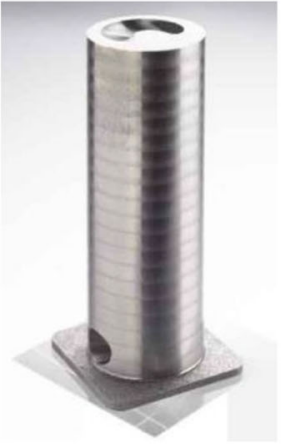

(a)

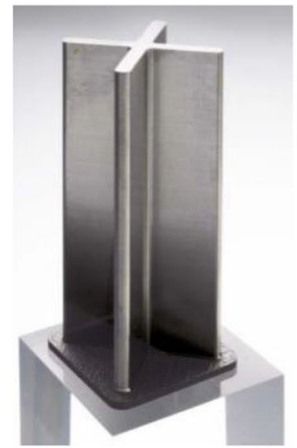

(b)

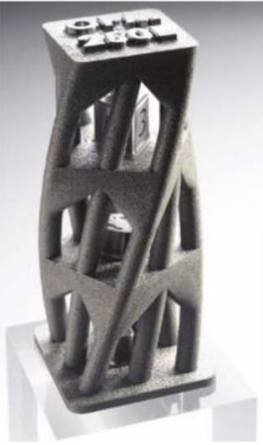

(c)

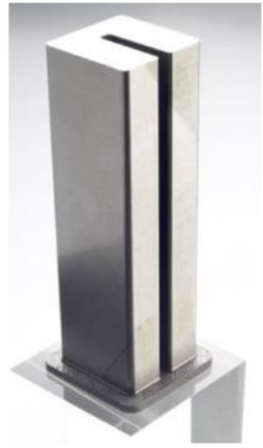

(d) repaired with the conventional welding methods. Figure 24 depicts the stages in the die repair process.

Bennet et al. [167] investigated the capabilities of a DLD head when integrated into a hybrid AM solution when applied for repairing automotive dies. First, the damaged areas of the die were removed through machining and then they were rebuilt with the DLD process. H13 dies were repaired with the hybrid process and also with the conventional TIG process for comparison. It was stated that the repaired die with the hybrid AM process had the same life span as that processed with the conventional TIG method. Recently, Zhang et al. [168] reported a hybrid process that combined reverse engineering, prerepair processing, AM and material testing. The proposed method was applied for the repair of a H13 die with different types of defects. First, worn out sections were scanned to recreate the $3 \mathrm{D}$ model of the die. Then, these sections were machined out and heat treated to prepare them for the AM process. Next, the worn out sections were restored with the DLD process and finally their microstructure and mechanical properties were analysed. The results showed that a strong bonding was achieved between the deposited material and the pre-machined die. In another research, Foster et al. [62] investigated the feasibility of combining the DLD technology with finishing machining into a hybrid AM system for repairing dies by cladding Stellite cobalt-based alloy onto the worn out areas. The repaired die was subjected to hot forging, and it was reported that the die performance was the same or better when compared with that of a standard die. In particular, it was noted that the adhesive and abrasive wear modes of the repaired die performed better than the standard one.

Figure 25 shows common defects that appear in dies and moulds that could be repaired by employing hybrid AM solutions.

Repair of other high value components by using hybrid AM approaches was also reported in the literature. Le et al. [171] proposed a process planning approach for combining AM with subtractive operations. The methodology enables the repair of parts with high accuracy and thus avoiding the material recycling stage. The workflow for conducting a part repair with this hybrid method includes the following three steps: (1) a pre-processing stage, at which an inspection of the worn-out part is conducted; (2) a processing stage, at which AM, subtractive, inspection and heat treatment operations are combined; and (3) a post-processing stage, at which the final inspection of the part is conducted.

Praniewicz et al. [172] investigated a hybrid AM solution for DLD of Stellite alloy on 410 stainless steel substrates. The deposited material on the workpieces was analysed to assess the effect of process parameters on their internal and external porosity, microstructure and surface roughness. In particular, preliminary experiments were conducted first and thus
Fig. 21. Applications of a hybrid LPBF and machining solution developed by Sodick. a EV connector. b Switch box. c Duct shape core [162]

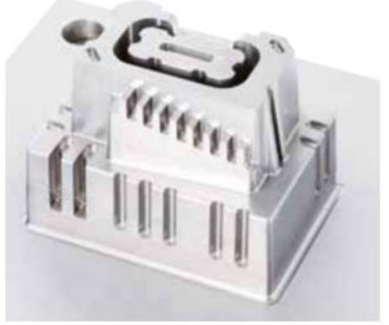

(a)

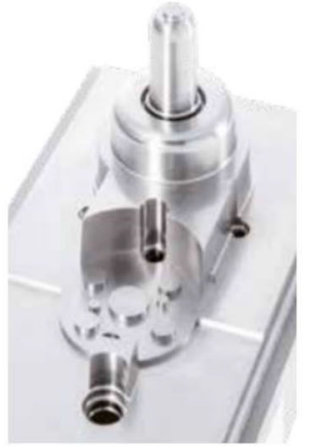

(b)

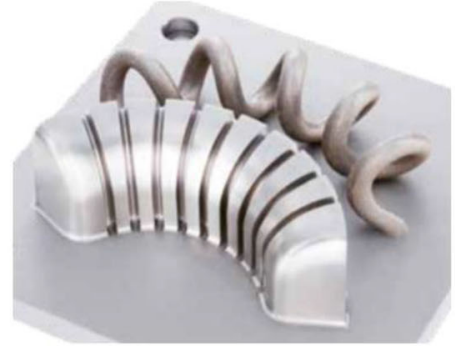

(c) 


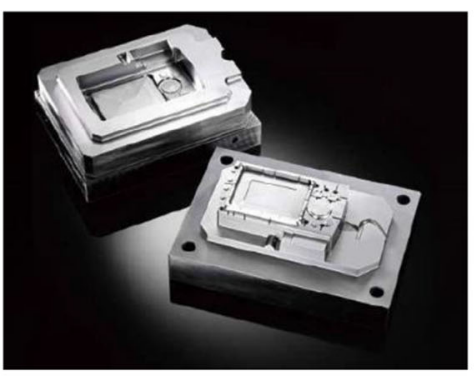

(a)

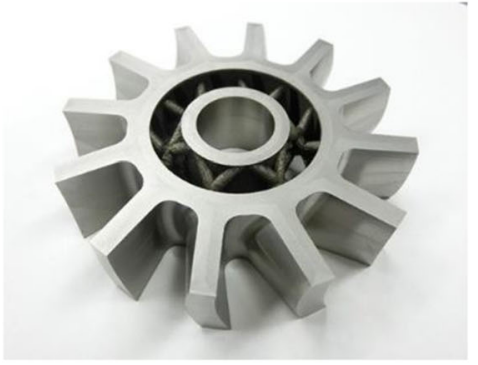

(d)

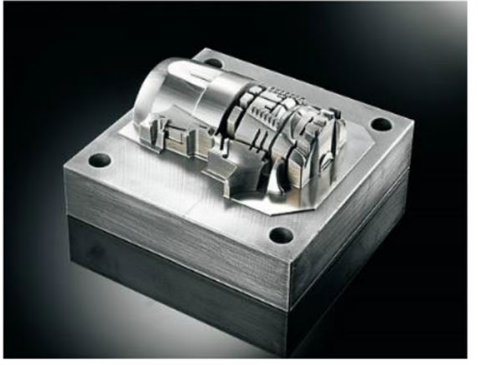

(b)

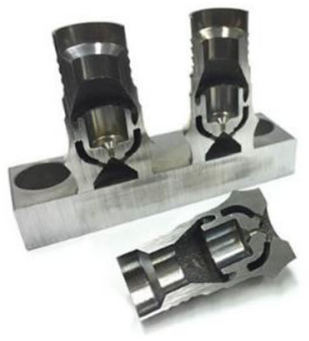

(e)

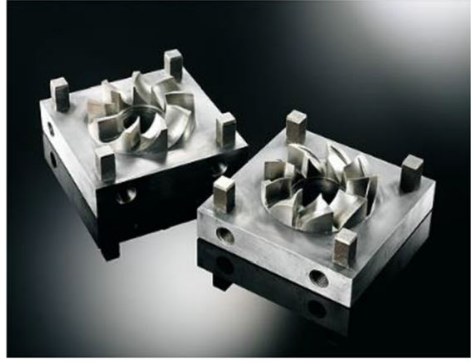

(c)

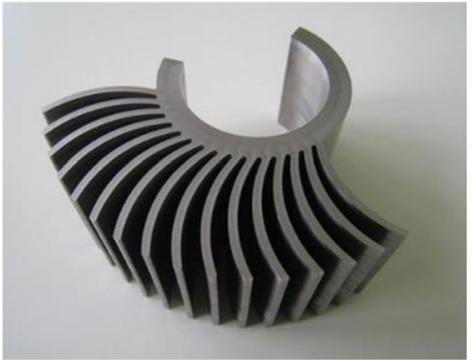

(f)

Fig. 22 Hybrid AM applications by Matsuura Lumex Series Hybrid machine, i.e. mould tools for digital camera (a), electric driver (b) and the manufacture of a fan (c); and products for blisks (d), jet engine nozzles (e) and cooling fins (f) [163]

optimising the process parameters. Then, a disc-shaped cylinder was manufactured with the optimised parameters. It was reported that in spite of the fact that some areas were inspected, the DLD process led to some flaws in the part, including surface voids and internal cracking.

Figure 26 shows examples of repaired parts for different industry applications where hybrid AM solutions were applied.

\subsection{Functionally graded materials}

The DLD technology provides capabilities for depositing different materials on components and thus enabling their manufacture from so-called functionally graded materials (FGM) and specially tailored alloys. FGM are characterised by variations of materials or their microstructures across the deposited sections and thus properties and functionality can be varied at different locations within the part volume [173]. The gradual changes of constituents along certain direction provide graded macroscopic and microstructures properties, such as hardness, wear resistance, corrosion resistivity, etc. In fact, some of the hybrid AM system list in Table 4 have the capabilities for multi-material deposition. In particular, Lasertec 65 3D from DMG Mori and Integrex I-400 AM from Yamazaki Mazak allow multi-material depositions and thus building FGM sections and parts. Many research groups have analysed FGM parts produced employing different hybrid AM solutions [174-182].

Figure 27 shows a schematic diagram of FGM [183] combining Haynes 282 material with progressively increasing amount of SiC. As depicted, the composition and properties of the materials can be changed from one end to another along the Z-axis. However, depending on the applications, there might also be changes from centre to end [174].

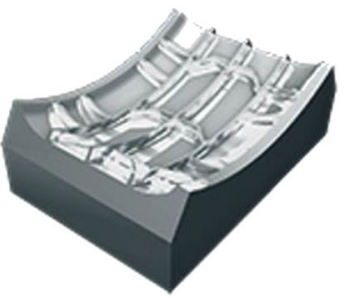

(a)

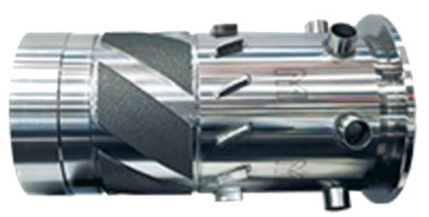

(b)

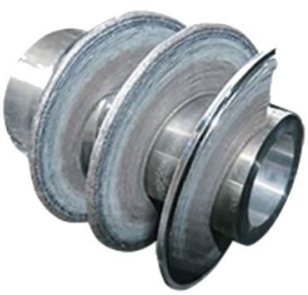

(c)

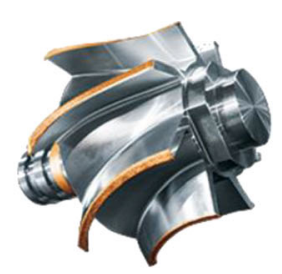

(d)

Fig. 23 Hybrid AM applications of the Mazak Integrex i-400AM system. a A mould insert. b, c General machinery. d Surface coating added to an impeller [164] 


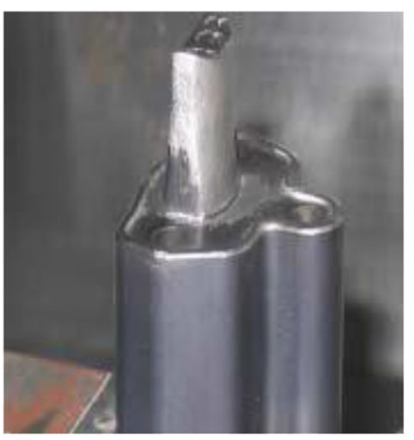

(a)

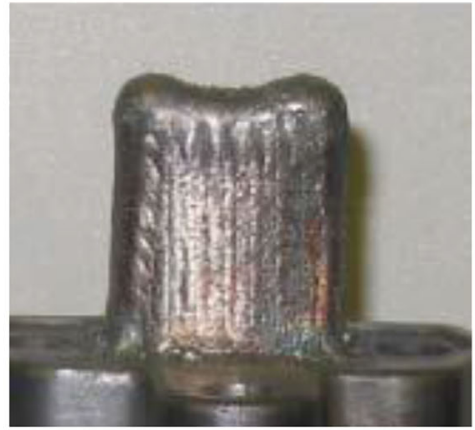

(b)

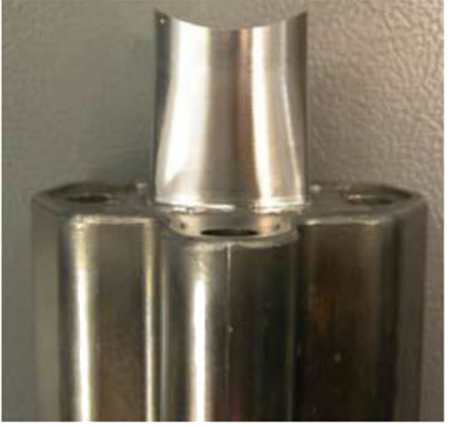

(c)

Fig. 24 A die core repair with a hybrid AM solution. a A worn out die before the repair. b After the DLD operation. $\mathbf{c}$ After the machining operation [166]

Figure 28 shows an example of an FGM application, in which different materials are employed for the substrate (steel) and for the deposition (copper).

Liu et al. [175] deposited a TiC/Ti composite employing the DLD process and graded the composition from $100 \% \mathrm{TiC}$ to almost $95 \% \mathrm{Ti}$ across the part. The DLD head consisted of four coaxial nozzle around the laser beam and two powder feeders with controlled deposition rates were used to deliver $\mathrm{Ti}$ and TiC powders. Results showed that the DLD system produced successfully FGM samples while prevented the crack formation. Li et al. [176] used again a DLD system to create FGM by gradually varying the composition from
Ti6A14V to SS316. A transition composition route was employed, i.e. as follows Ti6Al4V $\rightarrow \mathrm{V} \rightarrow \mathrm{Cr} \rightarrow \mathrm{Fe} \rightarrow$ SS316, with the aim of avoiding the development of intermetallic phases between Ti6Al4V and SS316 and thus producing a thin wall sample. A gradual transition in composition was achieved to produce a structure with no cracks or intermetallic phases between Ti6A14V and SS316 alloys. Chen et al. [177] deployed the DLD process to deposit 316L/Inconel 625 FGM. Initially, the composition was $100 \% 316 \mathrm{~L}$ stainless steel and then gradually it was changed to $100 \%$ Inconel 625 . FGM parts with a homogenous microstructure were produced while the material composition was varied continuously. A good

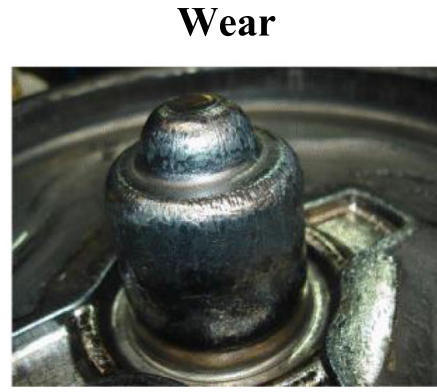

(a)

Fatigue

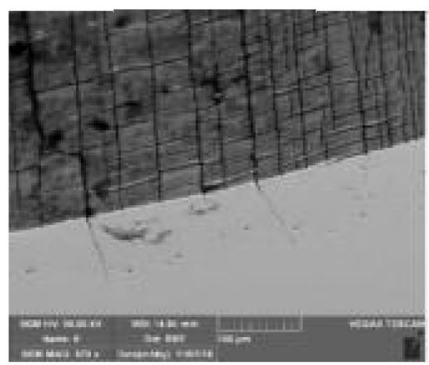

(d)
Crack and fracture

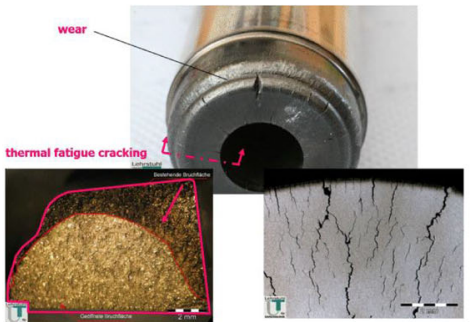

(b)

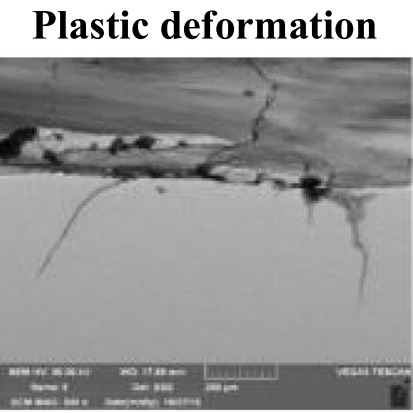

(e)

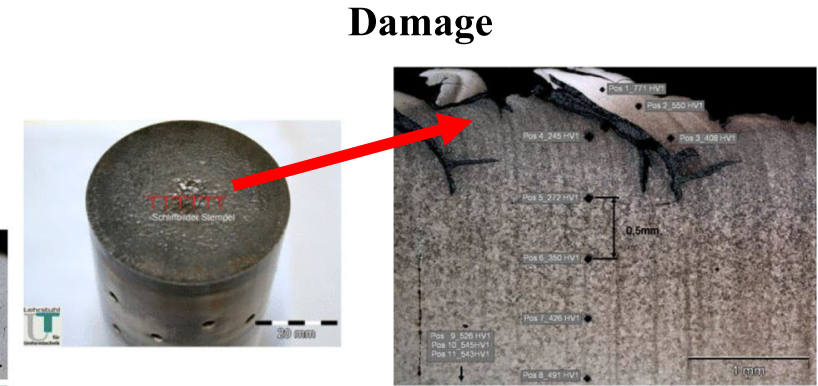

(c)

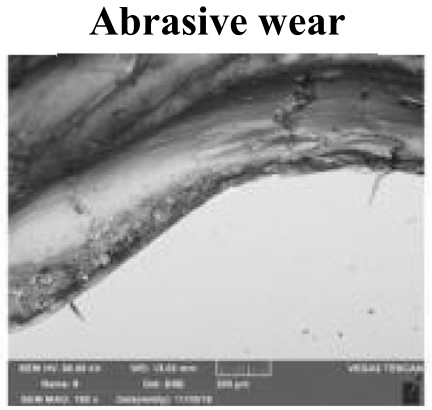

(f)
Oxidation

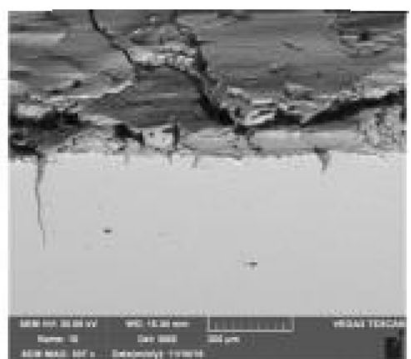

(g)

Fig. 25 Defects in dies and moulds that could be repaired by employing hybrid AM solutions $[169,170]$ 
Fig. 26 Parts repaired with hybrid AM solutions. a A turbo impeller. b Sheet metal mould [164]

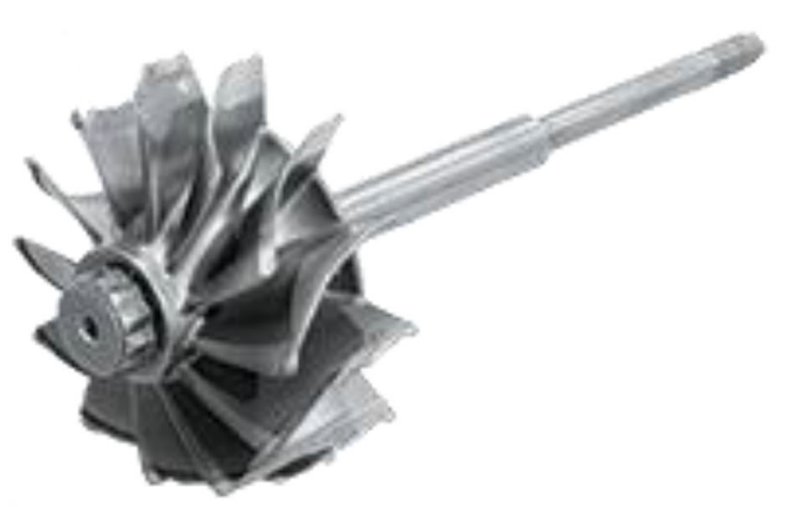

(a)

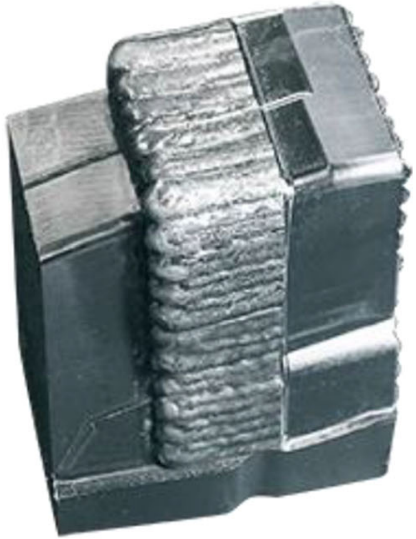

(b) linear gradient between $\mathrm{Fe}$ and $\mathrm{Ni}$ was achieved as a result of the good diffusion and the strong bonding between the deposited layers.

The FGM concept has been applied in several application areas, e.g. to produce transport systems, energy transfer systems, cutting tools, machine elements, optics, biomedical components, etc. FGM are of special interest for producing structural parts that require combinations of characteristics that cannot be found in a single material, e.g. hardness with toughness, or chemical inertness with toughness [178]. Table 5 includes some potential FGM applications with their respective industrial sectors.

FGM have a wide range of applications, and hybrid AM solutions are important enablers for producing FGM parts.
Especially, the hybrid AM route can enable the manufacture of end-use parts with high surface quality, dimensional accuracy and tailored mechanical properties.

\section{Challenges of hybrid additive manufacturing}

Hybrid AM solutions can address many of AM limitations and challenges; however, they have their own specific challenges that limit the broader use of this promising technology by industry. This section discusses the main challenges of the hybrid AM technology for producing metal parts.
Fig. 27 A schematic representation of functionally graded materials [183]

\begin{tabular}{|c|c|}
\hline Layer 16 & $85 \%$ Haynes $282+15 \%$ SiC \\
\hline Layer 15 & $86 \%$ Haynes $282+14 \% \mathrm{SiC}$ \\
\hline Layer 14 & $87 \%$ Haynes $282+13 \% \mathrm{SiC}$ \\
\hline Layer 13 & $88 \%$ Haynes $282+12 \% \mathrm{SiC}$ \\
\hline Layer 12 & $89 \%$ Haynes $282+11 \% \mathrm{SiC}$ \\
\hline Layer 11 & $90 \%$ Haynes $282+10 \% \mathrm{SiC}$ \\
\hline Layer 10 & $91 \%$ Haynes $282+9 \% \mathrm{SiC}$ \\
\hline Layer 9 & $92 \%$ Haynes $282+8 \% \mathrm{SiC}$ \\
\hline Layer 8 & $93 \%$ Haynes $282+7 \% \mathrm{SiC}$ \\
\hline Layer 7 & $94 \%$ Haynes $282+6 \% \mathrm{SiC}$ \\
\hline Layer 6 & $95 \%$ Haynes $282+5 \% \mathrm{SiC}$ \\
\hline Layer 5 & $96 \%$ Haynes $282+4 \% \mathrm{SiC}$ \\
\hline Layer 4 & $97 \%$ Haynes $282+3 \% \mathrm{SiC}$ \\
\hline Layer 3 & $98 \%$ Haynes $282+2 \% \mathrm{SiC}$ \\
\hline Layer 2 & $99 \%$ Haynes $282+1 \% \mathrm{SiC}$ \\
\hline Layer 1 & $100 \%$ Haynes \\
\hline
\end{tabular}

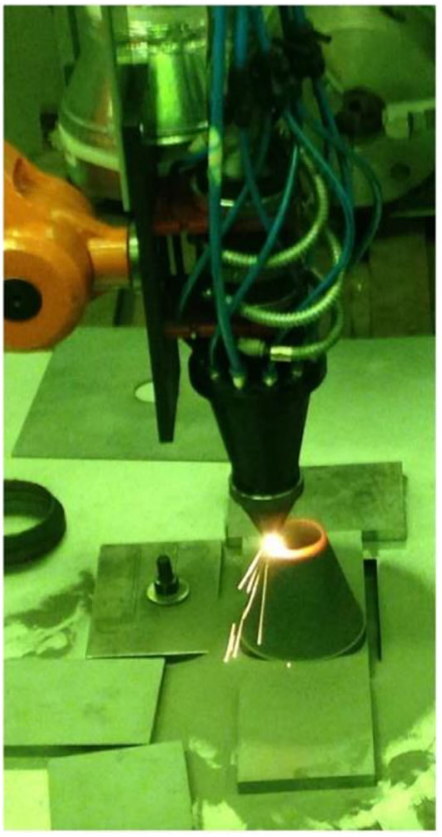


Table 5 Examples of FGM applications in different industries

\begin{tabular}{lll}
\hline Industry & Application & Reference \\
\hline Biomedical & Femoral stem protheses & {$[179-181]$} \\
Energy industry & $\begin{array}{l}\text { Dental implant } \\
\text { Heat exchange panels }\end{array}$ & {$[182]$} \\
Automotive & $\begin{array}{l}\text { Engine cylinder liners } \\
\text { Combustion chambers }\end{array}$ & {$[182]$} \\
Aerospace & Rocket nozzle & {$[182]$} \\
& Wings & \\
\hline
\end{tabular}

Strong et al. [185] reported a survey among traditional manufacturers that highlighted the open issues associated with the access of metal AM systems, process engineering, tooling requirement (tool access) and part quality control. In addition, it was noted that hybrid processes combining AM with machining technologies are not yet applicable in many industrial sectors due to the size limitations of AM systems.

\subsection{Materials and machinability}

The machinability of metal AM parts is one of the main open issues that prevent the broader take up of hybrid AM solutions. In addition, the intrinsic characteristics of metal AM processes affect directly the machinability of the compacted powder through laser-material interactions. In particular, during material deposition operations, parts are subjected to high thermal gradients, i.e. high heat and cooling rates, that lead to a higher strength and hardness of the compacted powder and consequently to higher cutting forces and tool wear rates [186]. Milton et al. [187] reported that the increase of cutting forces was possibly due to microstructural discontinuities of AM components, which entailed higher wear rates and lower tool life.

The most common materials and alloys employed in metal AM processes can be clustered into stainless steel alloys (316L, 17-4PH, etc.), nickel-based and cobaltbased superalloys (Inconel 625, Inconel 718, CoCrF25, etc.), titanium alloys (Ti6Al4V, CPTi, etc.) and aluminium alloys (AlSi10Mg, etc.). Some of these alloys on their own are considered difficult-to-machine materials due to their outstanding mechanical properties that are maintained even at high temperatures. Table 6 summarises the machinability of the alloys that are commonly employed in metal AM processes.

Machinability of materials is related to tool wear modes and chip formation characteristics during cutting and also affects the surface and microstructural characteristics of the machined samples.

A research on turning DLD Ti6Al4V parts was conducted by Oyelola et al. [192] to study their machining behaviour and resulting microstructural and surface integrity changes. It was noted that microstructural inhomogeneity of deposited material had a negative impact on surface integrity and machinability of the manufactured part. Furthermore, it was stated that the control system used for the machining operations should be able to adapt to varying cutting forces and conditions in order to obtain the best machining performance. This requirement can be explained with microstructural inhomogeneity of

Table 6 Metallic materials and alloys that are commonly employed in AM applications

\begin{tabular}{|c|c|c|c|}
\hline Material & Definition & Machinability & Application examples \\
\hline Stainless steel & $\begin{array}{l}\text { Chromium content higher than } 11 \% \\
\text { [188] }\end{array}$ & Lower machinability than common steels & $\begin{array}{l}\text { Energy industry (fossil fuel energy plants), } \\
\text { biomedical industry (implants) automo- } \\
\text { tive industry (exhaust systems) }\end{array}$ \\
\hline $\begin{array}{l}\text { Nickel-based } \\
\text { superalloys }\end{array}$ & Higher than $50 \%$ nickel content [189] & $\begin{array}{l}\text { Difficult to machine as they maintain good } \\
\text { mechanical properties at high temperatures } \\
{[188,189] \text {. These alloys have a great affinity }} \\
\text { to common cutting tools' materials that leads } \\
\text { to high tool wear rates [190]. }\end{array}$ & $\begin{array}{l}\text { Aircraft turbine components that are } \\
\text { exposed to high temperatures }\end{array}$ \\
\hline $\begin{array}{l}\text { Cobalt-based } \\
\text { superalloys }\end{array}$ & $\begin{array}{l}\text { Cobalt-based alloys have similar } \\
\text { properties, i.e. high hardness and } \\
\text { wear resistance, and low thermal } \\
\text { conductivity [191]. }\end{array}$ & $\begin{array}{l}\text { Difficult to machine as they maintain good } \\
\text { properties at high temperatures }[188,189] \text {. } \\
\text { Cobalt-based alloys also lead to high tool } \\
\text { wear rates. }\end{array}$ & $\begin{array}{l}\text { Aerospace industry (turbine and rocket } \\
\text { motors), submarine and chemical } \\
\text { industries (nuclear reactors, heat } \\
\text { exchangers and gas turbines) }\end{array}$ \\
\hline Titanium alloys & $\begin{array}{l}\text { Excellent combination of wear } \\
\text { resistance and hardness and good } \\
\text { corrosion behaviour [188] }\end{array}$ & $\begin{array}{l}\text { During machining, these alloys tend to } \\
\text { generate crater wear on cutting tools. }\end{array}$ & Biomedical industry (hip implants) \\
\hline Aluminium alloys & $\begin{array}{l}\text { They were the first type of alloys } \\
\text { employed in high performance } \\
\text { machining applications due to their } \\
\text { high machinability. }\end{array}$ & $\begin{array}{l}\text { Malleable alloys lead to the generation of BUE } \\
\text { (built-up-edge) wear mode in the cutting } \\
\text { tools. Cast alloys lead to cutting tool } \\
\text { abrasion due to the presence of silicon in the } \\
\text { alloys that is a highly abrasive element. }\end{array}$ & $\begin{array}{l}\text { Automotive industry (wheels), industrial } \\
\text { machinery and tool industry, thermal } \\
\text { and electric installations }\end{array}$ \\
\hline
\end{tabular}


AM parts and would be especially valid for FGM. In another study, Hojati et al. [193] investigated the machinability of AM Ti-based alloys and it was compared with that of a standard material in terms of cutting forces, specific cutting energy, surface quality and chip formation mechanism. The results showed that there were no significant differences in regards to the cutting forces. However, the machining of AM samples led to the formation of continuous wavy-type chips that were larger than those of the standard samples. Aldwell et al. [194] compared the machining of bulk and AM A16061 samples, i.e. the cutting forces, the chip formation mechanism and the resulting surface morphology. It was concluded that a good machinability of AM samples could be achieved when there was a strong bonding between the layers and also when the part porosity was low. Therefore, the optimisation of process parameters for producing AM parts with higher homogeneity and minimum porosity is critical in order to improve their machinability.

Guo et al. [16] analysed the effect of the building direction during the DLD process on mechanical properties, microstructure and machinability of AISI 316L samples. Two building directions were investigated, and then the produced samples were machined by dry milling to meet the requirements for surface integrity and dimensional accuracy. It was found that the homogeneity and microstructure of the produced AM parts were dependent on the build direction and as a consequence the cutting forces, the tool wear and the resulting surface roughness deferred, too. It was concluded that some anisotropic characteristics of AM parts could be beneficial for the follow-up machining operations. Calleja et al. [195] studied the machinability of Inconel 718 samples produced with a hybrid AM process that combined DLD with machining. Cutting forces and specific cutting energy during turning and milling operations together with the resulting roughness and microhardness of the heat-treated DLD samples were compared with the results obtained for standard Inconel 718 samples. It was found that the cutting forces and microhardness were higher for the AM samples while the best surface roughness was obtained for the standard samples.

In summary, it can be stated that the machinability of AM parts is not sufficiently investigated and also taking into account the constantly growing number of AM materials, further research is required. In addition, the laser-material interactions when processing metallic powders should be studied further to understand better the underlying conditions that lead to the formation of hardened phases and non-uniform microstructures and thus are detrimental to the machinability of AM components.

\subsection{Part deformations}

The control of dimensional and geometrical accuracy of AM parts in time is another challenging issue in broadening the use of hybrid AM solutions. Residual stresses generated during the AM process can lead to part deformations and distortions. Therefore, post-processing operations have to be properly planned considering the actual geometry and dimensions of the AM parts and thus ensuring the required accuracy with respect to their design. As a result, part inspections are very important in planning post-processing operations and thus determining the actual deviations of AM part geometries from their intended designs.

The uncertainty of additively manufactured part dimensions is one of the greatest concerns when combining both additive and machining processes. During the machining processes, tool may find excess of material in non-expected places, which can cause tool damage or inadequate cutting [196]. Therefore, a great effort has been made to understand and control part deformations during AM. Paul et al. [197] proposed a model for calculating the deformation of workpiece during AM processes that are due to thermal stresses. It was found that the overlap between successive scanning paths, also referred to as hatch spacing, leads to continuous melting and re-solidification cycles that, in turn, determines the accumulated thermal stresses. Consequently, the developed stresses entail part distortions and dimensional inaccuracies. In addition to the hatch spacing, Das et al. [198] also studied the effects of layer thickness, support structures and build orientations on geometrical and dimensional accuracies of LPBF parts. It was found that the building direction was a crucial parameter as it affected the properties and dimensional accuracy of parts and determined the amount of support structures needed. An approach was proposed to define the optimal part orientation and thus minimising the support structures. However, the approach still required empirical data for validation purposes. In addition, the model did not consider some important factors in determining the optimal part orientations such as the resulting thermal stresses. Eisenbarth et al. [199] investigated the distortion of parts manufactured using two different hybrid AM approaches: (1) continuous DLD buildup of material with subsequent milling and (2) interrupted DLD build-up alternated with milling. It was shown that each consequent DLD step led to a higher bending of the developed part, whereas the milling steps reduce it to a certain degree. Also, it was noted that, an inspection operation was required between the deposition and machining stems due to the part distortions.

However, the inspection of certain regions, such as internal cavities or complex overhanging features is also a challenging task. A summary of different methods used for inspecting AM parts with their open issues and challenges is provided in Table 7 [200].

Laser-based inspection methods for AM parts were investigated, too. Montinaro et al. [201] used a flying laser scanning thermography for inspection of AM parts with high signal to noise ratio of the measurements. However, it was noted that 
Table 7 Inspection methods for AM parts with their open issues and challenges

\begin{tabular}{ll}
\hline Inspection method & Open issues and challenges \\
\hline Visual inspection & Limited to surface defect detection \\
& Internal and difficult-to-access regions cannot be examined. \\
Incompatible with porous materials \\
Oiquid penetration test \\
Only provides information about surface discontinuities. \\
Exclusive for ferromagnetic materials \\
No information about the bulk or internal features \\
Eddy current testing & Exclusive to electrically conductive materials \\
& Also detects unwanted signals. \\
Sophisticated algorithms for signal processing are required. \\
Inspection once the part is finished which may lead to rejection \\
at the end of manufacturing process [201]. \\
X-ray & Again, inspection of only finished parts which may lead to rejections \\
& at the end of the manufacturing process [201]. \\
\hline
\end{tabular}

due to the higher surface roughness of metal AM parts laserbased inspection methods might not be a suitable solution.

In addition, the integration of inspection operations into hybrid AM solutions should also be considered. Their maintenance and protection from fumes and cutting fluids together with the integration of inspection software with CAD/CAM software also present challenges and open issues in developing hybrid AM systems and thus increasing their efficiency and throughput.

\subsection{Process related challenges}

Hybrid AM solutions have open issues and challenges associated with each integrated technology and also due to the execution of all operations in the same manufacturing system. The main process-related issues in hybrid AM can be clustered into (1) process parameter optimisation, (2) cleanness, (3) material oxidation and (4) issues related to the AM processes.

The process optimisation is one of the shortcomings of metal AM technologies and also in hybrid AM systems. There is no sufficient knowledge how post-processing parameters might affect AM parts [81]. Considering the case when machining operations are used for post-processing AM parts, in spite of the fact that it is a mature technology, there is not sufficient research on their effects on the resulting surface integrity. Additionally, a key open issue in broadening the use of hybrid AM solutions is the achievable repeatability and thus whether they can meet the requirements for serial production. Especially, it is necessary to determine geometric and dimensional tolerances that can be achieved consistently together with respective mechanical and microstructure properties of the hybrid parts. A systematic analysis of various factors affecting the processing conditions of integrated processes is required. This will allow processing parameters and equipment accuracy and repeatability to be controlled sufficiently well to meet standardised requirements that are also yet to be developed.

Coolant management and cleanness, especially for the laser-based AM technologies, are other critical issues when integrating AM processes with conventional machining in hybrid AM systems $[81,196]$. The issues associated with cleanness were studied by Boivie et al. [123] and it was found that all chips and cutting fluids should be carefully removed before starting any AM process. Otherwise, it could deteriorate the machinability of difficult-to-cut materials such as Ti-based alloys or Ni-based alloys. As for the cutting fluid, it can be mixed with the powder particles and affect their absorptivity and, consequently, the bonding with the substrate material [196]. Additionally, machine guiding systems must be protected and properly sealed in order to avoid powder particles to abrade the moving components.

Another important issue in hybrid AM systems is the lack of a closed chamber to avoid powder oxidation during the AM processes. As was already mentioned, several hybrid AM systems utilised inert gases to shield processing areas and thus minimising the oxidation during laser-material interactions. However, depending on process parameters and reactivity of employed materials, this may not be sufficient to avoid any oxidation. In turn, the oxidation can induce defects in the manufactured parts. Hebert et al. [202] found that when the AM process utilised reactive materials such as titanium-based alloys, oxide layers might be formed in spite of shielding conditions except when using extremely high vacuum. In addition, the formation of hydroxides and hydrated oxides should also be addressed. While oxides tend to strengthen the materials, hydroxides can act as lubricants and deteriorate the strength of AM parts.

As it was already discussed, LPBF and DLD are the most commonly employed laser-based AM technologies and, in 
Fig. 28 Example of FGM: deposition of copper on a steel substrate [184]

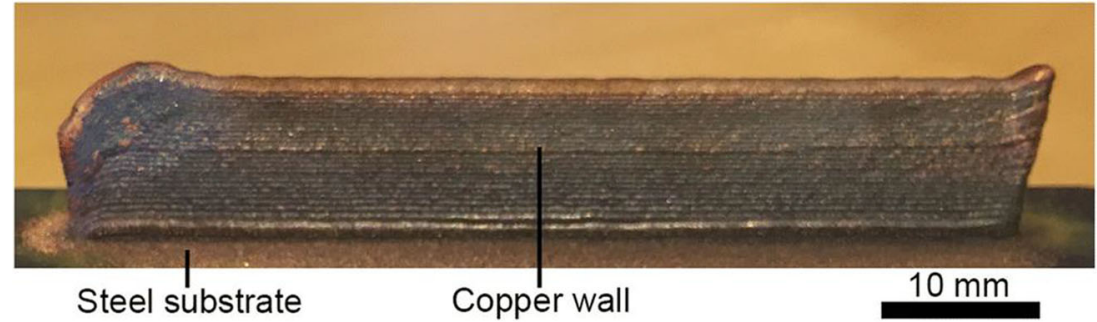

\subsection{Work holding-related challenges}

systems, too. LPBF enables the creation of complex parts with high accuracy, but it is a relatively slow process. In addition, support structures have to be removed in follow-up post-processing operations. Depending on the geometry and the location of those support structures, their removal can represent a challenge if they are difficult to reach with the cutting tools. Additionally, LPBF can be integrated only into 3-axis vertical machine tool configurations. Therefore, the LPBF capabilities for producing complex part geometries may be reduced due to the constraints imposed by post-processing operations. Furthermore, powder management is another important issue to consider in integrating the LPBF process in hybrid AM systems.

At the same time, the DLD technology is faster than the LPBF one and therefore any hybrid AM system that integrates a DLD head will have a higher throughput. Also, the DLD allows complex parts to be built without the need for support structures because of the higher positioning flexibility of the hybrid machine tool configurations. Nevertheless, the DLD head inclination and position have to be carefully controlled to maintain the optimum deposition rates and parts accuracies. However, there are some shortcomings, too, as the overall quality of DLD manufactured parts, i.e. their dimensional and geometrical accuracy and surface integrity, is worse than that of LPBF parts. Additionally, special care should be taken to avoid any collisions between the workpieces, the DLD head and the cutting tools during both deposition and postprocessing operations.
Machining of AM parts directly can be challenging because of their lightweight and complex shapes. These both characteristics can lead to problems with work holding and vibration, and thus can result in poor process yields. Work holding systems have to be designed and implemented in such a way that they should ensure reliable workpiece fixation and the required accuracy and repeatability during machining operations. Thus, these systems should be designed to withstand the cutting forces during machining operations without any displacements while providing sufficient access to all surfaces that require some post-processing. However, in the case of hybrid AM solutions, the geometries of the AM structures are complex and can incorporate internal cavities with different stiffness and properties. Therefore, the work holding systems have to be sufficiently flexible while providing adequate support for processing parts with varying geometries and rigidity. This is not an easy design and implementation task.

One of the solutions that have been proposed for holding the workpiece during the machining operations is depicted in Fig. 29. First, the workpiece has to be embedded into an auxiliary plastic support structure that is afterwards removed [203]. The configuration of the auxiliary support system should ensure both the required workpiece fixation during the machining operations and also access to the surfaces that should undergo some post-processing, e.g. the flat surfaces at both ends of the rectangular pipe in Fig. 29.
Fig. 29 A special clamping solution designed by Renishaw for holding AM workpieces during the machining operations. a The AM workpiece. b The work holding system [203]

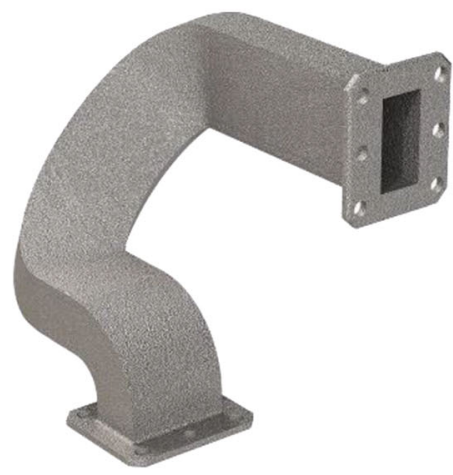

(a)

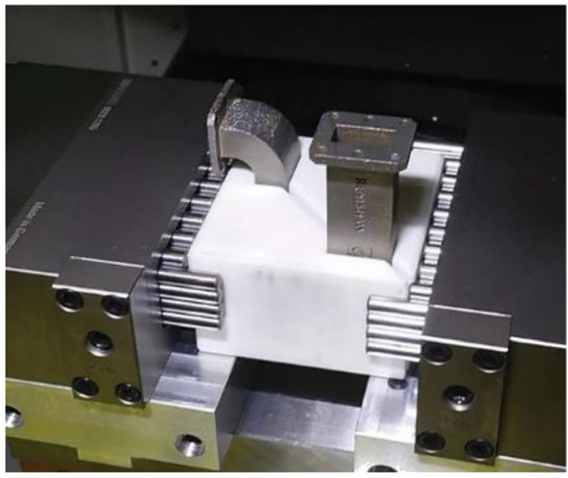

(b) 


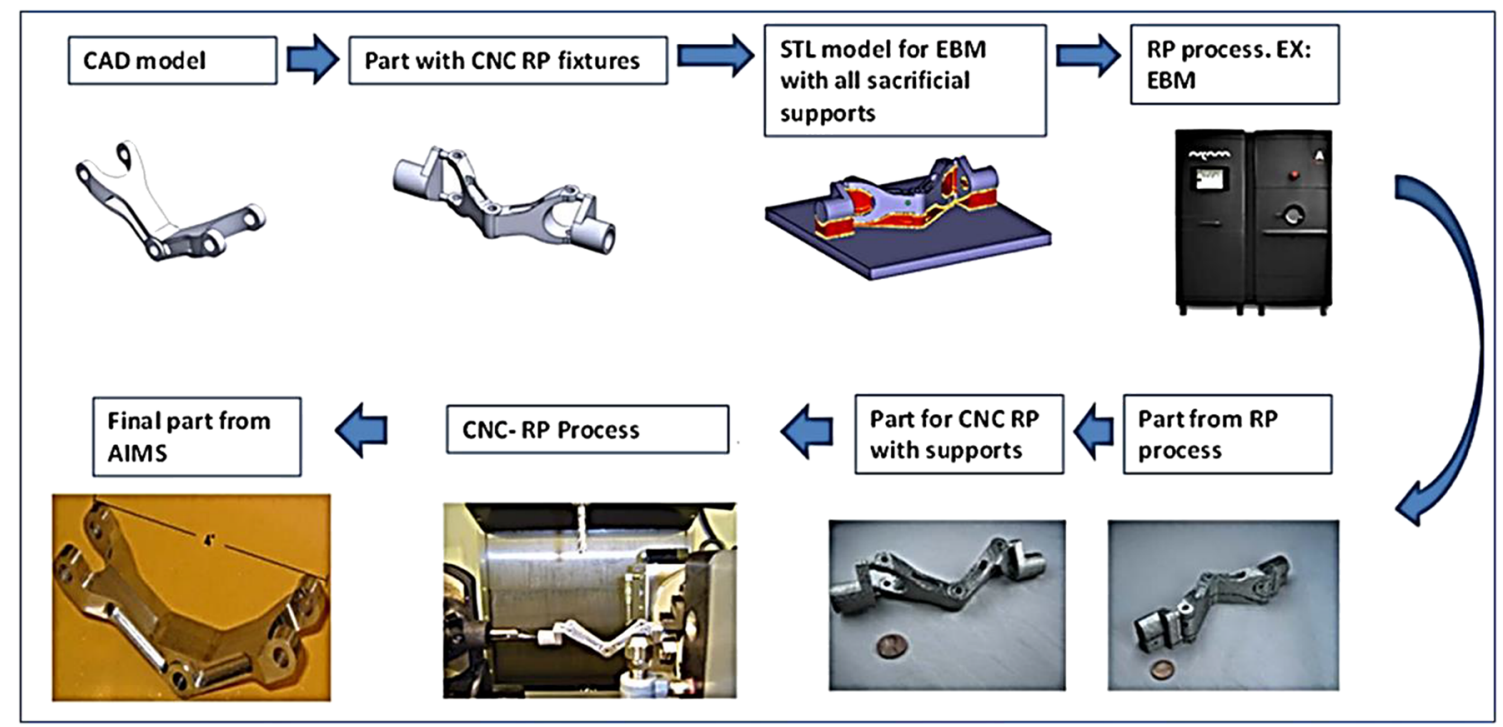

Fig. 30 Sacrificial features for part positioning [10]. The figures are reused under the Creative Commons CC-BY licence

Manogharan et al. [10] proposed another solution for clamping and positioning of AM workpiece that uses some sacrificial supports. Especially, the sacrificial support has to be built together with the workpiece during the AM process and thus ensure the required positioning and fixation during the machining operations. Figure 30 shows the workflow suggested in designing and implementing such work holding systems. As it can be seen, the CAD model of the part have to be modified to add required sacrificial features while at the end a further post-processing step is required to remove them.

One of the main advantages of using single setup hybrid additive manufacturing systems is that they enable to reduce the time to define part zeros. This is an advantage not only in terms of productivity of the process, but also because it minimises the positioning-error that occurs when using multisetup solutions [196]. In those cases that employ intermediate or special fixturing systems as the ones presented above, the design of rigid and appropriate fixturing systems will be of great importance to reduce those positioning problems.

\section{Conclusions}

The paper presents the research work on hybrid AM solutions that combine the capabilities of AM with post-processing technologies. The review has a special focus on powderbased AM processes that employ lasers as a heat source for material processing. Different hybrid AM solutions were reported and their capabilities and limitations were analysed. Additionally, an overview of commercially available hybrid AM systems is presented, too, that outline the machine specifications together with their advantages and limitations.
Furthermore, current and potential applications of hybrid $\mathrm{AM}$ are discussed. Finally, the open issues and main challenges associated with the hybrid AM solutions are discussed to suggest directions for future research. Especially, the open issues associated with machinability of common AM materials, part deformations, shortcomings of integrated processes and specially designed work holding systems are discussed.

The broader take up of metal AM technologies requires their seamless integration with post-processing technologies and thus addressing deficiencies of AM parts, i.e. their accuracy and surface integrity, and thus meeting the requirements of aerospace, automotive and biomedical industrial sectors. Hybrid AM solutions that integrate machining, heat and surface treatment operations have shown a clear potential to improve the surface finish, geometrical accuracy, mechanical properties and microstructures of metal AM components. The machining operations allow the required surface integrity and dimensional accuracy to be achieved while heat and surface treatments can be used to reduce porosity and improve the microstructure and mechanical properties of AM parts. Additionally, deformations and distortions of AM parts due to residual stresses along with other defects should be considered when planning the followup post processing operations. Therefore, the integration of part inspection solutions into the hybrid AM systems is crucial in order to produce parts that meet the industrial requirements.

Recently, hybrid AM solutions have attracted the interest of machine tool manufacturers and also of end-user companies and a significant number of hybrid machine tools have been developed in the last decade and are now commercially available. In addition, modular hybrid solutions have been developed, too, that can be integrated into existing machining or AM systems. It is evident that hybrid AM systems are very important in broadening the industrial application of metal 
AM technologies, especially in high-tech industries such as biomedical (dental applications and protheses), aerospace (turbine blisks, cases, etc.) or automotive (engine cylinders). Another key application of hybrid AM systems is the repair of high-value components and the manufacture of FGM parts with tailored mechanical properties.

In spite of all the benefits and the potential of hybrid AM systems shown so far, several open issues and challenges remain that have to be addressed, in particular:

- There is still not sufficient research on machinability of AM parts and optimisation of both AM and post processing technologies with a special focus on difficult-tomachine materials.

- The laser-material interactions when processing metallic powders should be studied further to understand better the underlying conditions that lead to the formation of hardened phases and non-uniform microstructures and thus are detrimental to the machinability of AM components.

- Issues related to AM processes, such as part distortion, varying and not constant mechanical properties and microstructure of produced AM parts, have to be considered and controlled when planning and implementing hybrid AM solutions.

- Powder oxidation in out-of-chamber AM processing, relatively low productivity, the necessity for removing any support structures and possible collisions are some other open issues preventing the broader use of the hybrid AM systems that have to be addressed.

Acknowledgements The authors would acknowledge the support received from the ESIF/ERDF Smart Factory Hub (SmartFub) programme in West Midlands. The authors also acknowledge the support received from Yamazaki Mazak, DMG MORI, LASEA and Systems 3R for establishing the hybrid AM facilities at the University of Birmingham.

Author contribution Amaia Jiménez: Conceptualization, analysis, investigation, writing of the original draft

Prveen Bidare: Conceptualization, analysis, investigation, writing of the original draft

Hany Hassanin: Writing review

Faris Tarlochan: Writing review

Stefan Dimov: Analysis and writing review

- Khamis Essa: Conceptualization, Analysis and Writing review.

Funding This study received funding from the European Union's Horizon 2020 research and innovation programme under grant agreement No 723826 (MAESTRO).

Data availability Not applicable.

\section{Declarations}

Ethics approval This paper is our original unpublished work, and it has not been submitted to any other journal for reviews.
Consent to participate All authors were fully involved in the study and preparation of the manuscript, and each of the authors has read and concurs with the content in the final manuscript.

Consent for publication All authors consent to publish the content in the final manuscript.

Competing interests The authors declare no competing interests.

Open Access This article is licensed under a Creative Commons Attribution 4.0 International License, which permits use, sharing, adaptation, distribution and reproduction in any medium or format, as long as you give appropriate credit to the original author(s) and the source, provide a link to the Creative Commons licence, and indicate if changes were made. The images or other third party material in this article are included in the article's Creative Commons licence, unless indicated otherwise in a credit line to the material. If material is not included in the article's Creative Commons licence and your intended use is not permitted by statutory regulation or exceeds the permitted use, you will need to obtain permission directly from the copyright holder. To view a copy of this licence, visit http://creativecommons.org/licenses/by/4.0/.

\section{References}

1. Essa K, Hassanin H, Attallah MM, Adkins NJ, Musker AJ, Roberts GT, Tenev N, Smith M (2017) Development and testing of an additively manufactured monolithic catalyst bed for HTP thruster applications. Appl Catal A Gen 542:125-135. https:// doi.org/10.1016/j.apcata.2017.05.019

2. Sabouri A, Yetisen AK, Sadigzade R, Hassanin H, K. Essa HB. (2017) Three-dimensional microstructured lattices for oil sensing. Energy Fuel 31(3):2524-2529

3. Li S, Hassanin H, Attallah MM, Adkins NJE, Essa K (2016) The development of TiNi-based negative Poisson's ratio structure using selective laser melting. Acta Mater 105:75-83. https://doi. org/10.1016/j.actamat.2015.12.017

4. Hassanin H, Alkendi Y, Elsayed M, Essa K, Zweiri Y (2020) Controlling the properties of additively manufactured cellular structures using machine learning approaches. Adv Eng Mater 22:1-9. https://doi.org/10.1002/adem.201901338

5. Hassanin H, Finet L, Cox SC, Jamshidi P, Grover LM, Shepherd DET, Addison O, Attallah MM (2018) Tailoring selective laser melting process for titanium drug-delivering implants with releasing micro-channels. Addit Manuf 20:144-155. https://doi.org/10. 1016/j.addma.2018.01.005

6. Springer (n.d.) https://www.springer.com/gp (accessed December 1, 2020).

7. Karunakaran KP, Suryakumar S, Pushpa V, Akula S (2010) Low cost integration of additive and subtractive processes for hybrid layered manufacturing. Robot Comput Integr Manuf 26:490-499. https://doi.org/10.1016/j.rcim.2010.03.008

8. Kerbrat O, Mognol P, Hascoët JY (2011) A new DFM approach to combine machining and additive manufacturing. Comput Ind 62: 684-692. https://doi.org/10.1016/j.compind.2011.04.003

9. 3dhubs. Producing metal parts - CNC vs. additive manufacturing n.d.

10. Manogharan G, Wysk R, Harrysson O, Aman R (2015) AIMS - A metal additive-hybrid manufacturing system: system architecture and attributes. Procedia Manuf 1:273-286. https://doi.org/10. 1016/j.promfg.2015.09.021

11. Tofail SAM, Koumoulos EP, Bandyopadhyay A, Bose S, O’Donoghue L, Charitidis C (2018) Additive manufacturing: 
scientific and technological challenges, market uptake and opportunities. Mater Today 21:22-37. https://doi.org/10.1016/j.mattod. 2017.07.001

12. About Additive manufacturing -directed energy deposition (n.d.) https://www.1boro.ac.uk/research/amrg/about/ the 7categoriesofadditivemanufacturing/directedenergydeposition/ (accessed March 13, 2020).

13. Zhang Y, Jarosinski W, Jung YG, Zhang J (2018) Additive manufacturing processes and equipment. Elsevier Inc. https:// doi.org/10.1016/B978-0-12-812155-9.00002-5

14. Yin S, Cavaliere P, Aldwell B, Jenkins R, Liao H, Li W, Lupoi R (2018) Cold spray additive manufacturing and repair: fundamentals and applications. Addit Manuf 21:628-650. https://doi.org/10. 1016/j.addma.2018.04.017

15. Bray M, Cockburn A, O'Neill W (2009) The laser-assisted cold spray process and deposit characterisation. Surf Coat Technol 203: 2851-2857. https://doi.org/10.1016/j.surfcoat.2009.02.135

16. Guo P, Zou B, Huang C, Gao H (2017) Study on microstructure, mechanical properties and machinability of efficiently additive manufactured AISI 316L stainless steel by high-power direct laser deposition. J Mater Process Technol 240:12-22. https://doi.org/ 10.1016/j.jmatprotec.2016.09.005

17. Milewski JO (2018) Corrosion News. vol. 69. https://doi.org/10. 1002/maco.201870124.

18. Azarniya A, Colera XG, Mirzaali MJ, Sovizi S, Bartolomeu F, St Weglowski MK et al (2019) Additive manufacturing of Ti-6Al$4 \mathrm{~V}$ parts through laser metal deposition (LMD): process, microstructure, and mechanical properties. J Alloys Compd 804:163191. https://doi.org/10.1016/j.jallcom.2019.04.255

19. King WE, Anderson AT, Ferencz RM, Hodge NE, Kamath C, Khairallah AMR (2015) Laser powder bed fusion additive manufacturing of metals; physics, computational, and materials challenges. Appl Phys Rev 2:41304

20. Bidare P, Bitharas I, Ward RM, Attallah MM, Moore AJ (2018) Fluid and particle dynamics in laser powder bed fusion. Acta Mater 142:107-120. https://doi.org/10.1016/j.actamat.2017.09. 051

21. Das S (2003) Physical aspects of process control in selective laser sintering of metals. Adv Eng Mater 5:701-711. https://doi.org/10. 1002/adem.200310099

22. Talib MM (2018) Mechanical properties of SLM-Titanium materials for biomedical applications: a review. Mater Today Proc 5: 17906-17913. https://doi.org/10.1016/j.matpr.2018.06.119

23. Igor S (2019) Aerospace applications of the SLM process of functional and functional graded metal matrix composites based on $\mathrm{NiCr}$ superalloys, vol c. Elsevier Inc. https://doi.org/10.1016/ b978-0-12-814062-8.00014-5

24. Gu DD, Meiners W, Wissenbach K, Poprawe R (2012) Laser additive manufacturing of metallic components: materials processes and mechanisms. Laser additive manufacturing of metallic components: Materials, processes and mechanisms. Int Mater Rev 57:133-164. https://doi.org/10.1179/1743280411Y.0000000014

25. Read N, Wang W, Essa K, Attallah MM (2015) Selective laser melting of AlSi10Mg alloy: process optimisation and mechanical properties development. Mater Des 65:417-424. https://doi.org/ 10.1016/j.matdes.2014.09.044

26. Kamath C, El-Dasher B, Gallegos GF, King WE, Sisto A (2014) Density of additively-manufactured, 316L SS parts using laser powder-bed fusion at powers up to $400 \mathrm{~W}$. Int J Adv Manuf Technol 74:65-78. https://doi.org/10.1007/s00170-014-5954-9

27. Dadbakhsh S, Hao L (2014) Effect of layer thickness in selective laser melting on microstructure of $\mathrm{Al} / 5 \mathrm{wt} \% \mathrm{Fe} 2 \mathrm{O} 3$ powder consolidated parts. Sci World J 2014. https://doi.org/10.1155/2014/ 106129

28. Ferrar B, Mullen L, Jones E, Stamp R, Sutcliffe CJ (2012) Gas flow effects on selective laser melting (SLM) manufacturing performance. J Mater Process Technol 212:355-364. https://doi. org/10.1016/j.jmatprotec.2011.09.020

29. Louvis E, Fox P, Sutcliffe CJ (2011) Selective laser melting of aluminium components. J Mater Process Technol 211:275-284. https://doi.org/10.1016/j.jmatprotec.2010.09.019

30. Moda O (n.d.) Renishaw AM delivers fast parts at Ferrari F1. Renishaw

31. Herzog D, Bartsch K, Bossen B (2020) Productivity optimization of laser powder bed fusion by hot isostatic pressing. Addit Manuf 36:101494. https://doi.org/10.1016/j.addma.2020.101494

32. Shi G, Guan C, Quan D, Wu D, Tang L, Gao T (2020) An aerospace bracket designed by thermo-elastic topology optimization and manufactured by additive manufacturing. Chin J Aeronaut 33: 1252-1259. https://doi.org/10.1016/j.cja.2019.09.006

33. López-Castro JD, Marchal A, González L, Botana J (2017) Topological optimization and manufacturing by direct metal laser sintering of an aeronautical part in $15-5 \mathrm{PH}$ stainless steel. Procedia Manuf 13:818-824. https://doi.org/10.1016/j.promfg. 2017.09.121

34. Li R, Shi Y, Wang Z, Wang L, Liu J, Jiang W (2010) Densification behavior of gas and water atomized 316L stainless steel powder during selective laser melting. Appl Surf Sci 256: 4350-4356. https://doi.org/10.1016/j.apsusc.2010.02.030

35. RenAM 500Q multi-laser AM system. Renishaw PLC 2017. https://resources.renishaw.com/en/details/data-sheet-renam500q\%2D\%2D99032 (accessed March 17, 2020).

36. MetalFAB1. Addit Ind 2015. https://www.additiveindustries.com/ systems/metalfab1 (accessed March 17, 2020).

37. Bidare P, Bitharas I, Ward RM, Attallah MM, Moore AJ (2018) Laser powder bed fusion at sub-atmospheric pressures. Int J Mach Tools Manuf 130-131:65-72. https://doi.org/10.1016/j. ijmachtools.2018.03.007

38. Bidare P, Maier RRJ, Beck RJ, Shephard JD, Moore AJ (2017) An open-architecture metal powder bed fusion system for in-situ process measurements. Addit Manuf 16:177-185. https://doi.org/10. 1016/j.addma.2017.06.007

39. Bidare P, Bitharas I, Ward RM, Attallah MM, Moore AJ (2018) Laser powder bed fusion in high-pressure atmospheres. Int J Adv Manuf Technol 99:543-555. https://doi.org/10.1007/s00170-0182495-7

40. Concept laser. GE Addit 2015. https:/www.ge.com/additive/de/ who-we-are/concept-laser (accessed April 6, 2020).

41. EOSTATE monitoring and quality assurance - real-time monitoring for industrial 3D printing. Eos (Washington DC) 2017. https:// www.eos.info/software/monitoring-software (accessed April 6, 2020).

42. Sercombe TB, Xu X, Challis VJ, Green R, Yue S, Zhang Z, Lee PD (2015) Failure modes in high strength and stiffness to weight scaffolds produced by selective laser melting. Mater Des 67:501508. https://doi.org/10.1016/j.matdes.2014.10.063

43. Beretta S, Romano S (2017) A comparison of fatigue strength sensitivity to defects for materials manufactured by AM or traditional processes. Int J Fatigue 94:178-191. https://doi.org/10. 1016/j.ijfatigue.2016.06.020

44. Graff P, Ståhlbom B, Nordenberg E, Graichen A, P. Johansson HK. (2016) Evaluating measuring techniques for occupational exposure during additive manufacturing of metals: a pilot study. J Ind Ecol:1-10

45. Kruth JP, Froyen L, Van Vaerenbergh J, Mercelis P, Rombouts M, Lauwers B (2004) Selective laser melting of iron-based powder. J Mater Process Technol 149:616-622. https://doi.org/10.1016/j. jmatprotec.2003.11.051

46. Yadroitsev I, Bertrand P, Smurov I (2007) Parametric analysis of the selective laser melting process. Appl Surf Sci 253:8064-8069. https://doi.org/10.1016/j.apsusc.2007.02.088 
47. Mumtaz KA, Hopkinson NPE (2006) High density selective laser melting of waspaloy. J Mater Process Technol 195:220-232

48. Spierings AB, Herres N, Levy G (2011) Influence of the particle size distribution on surface quality and mechanical properties in AM steel parts. Rapid Prototyp J 17:195-202. https://doi.org/10. 1108/13552541111124770

49. Liu B, Wildman R, Tuck C, Ashcroft I, Hague R (2011) Investigation the effect of particle size distribution on processing parameters optimisation in selective laser melting process. 22nd Annu Int Solid Free Fabr Symp - An Addit Manuf Conf SFF 2011:227-38

50. Yadroitsev I, Thivillon L, Bertrand P, Smurov I (2007) Strategy of manufacturing components with designed internal structure by selective laser melting of metallic powder. Appl Surf Sci 254: 980-983. https://doi.org/10.1016/j.apsusc.2007.08.046

51. Simonelli M, Tuck C, Aboulkhair NT, Maskery I, Ashcroft I, Wildman RH (2015) A Study on the laser spatter and the oxidation reactions during selective laser melting of $316 \mathrm{~L}$ stainless steel, AlSi10-Mg, and Ti-6Al-4V. Metall Mater Trans A 46:3842-3851

52. Kempen K, Thijs L, Vrancken B, Buls S, Van Humbeeck J, Kruth JP (2013) Producing crack-free, high density M2 HSS parts by selective laser melting: pre-heating the baseplate. 24th Int SFF Symp - An Addit Manuf Conf SFF 2013:131-9

53. Morozova LV, Raevskikh AN (2020) Defects in metal components produced by selective laser melting. Russ Eng Res 40:3843. https://doi.org/10.3103/S1068798X20010153

54. Thompson SM, Bian L, Shamsaei N, Yadollahi A (2015) An overview of direct laser deposition for additive manufacturing; Part I: Transport phenomena, modeling and diagnostics. Addit Manuf 8:36-62. https://doi.org/10.1016/j.addma.2015.07.001

55. Löffler K (2013) Developments in disk laser welding. Handb Laser Weld Technol:73-102. https://doi.org/10.1533/ 9780857098771.1.73

56. Bax B, Rajput R, Kellet R, Reisacher M (2018) Systematic evaluation of process parameter maps for laser cladding and directed energy deposition. Addit Manuf 21:487-494. https://doi.org/10. 1016/j.addma.2018.04.002

57. Terrassa KL, Smith TR, Jiang S, Sugar JD, Schoenung JM (2019) Improving build quality in directed energy deposition by crosshatching. Mater Sci Eng A 765:138269. https://doi.org/10.1016/j. msea.2019.138269

58. Zhu G, Shi S, Fu G, Shi J, Yang S, Meng W, Jiang F (2017) The influence of the substrate-inclined angle on the section size of laser cladding layers based on robot with the inside-beam powder feeding. Int J Adv Manuf Technol 88:2163-2168. https://doi.org/10. 1007/s00170-016-8950-4

59. Kelbassa MSJ, Gasser A, Pirch N (2018) WIRE VS. POWDER IN LMD. Fraunhofer ILT

60. Petrat T, Graf B, Gumenyuk A, Rethmeier M (2016) Laser metal deposition as repair technology for a gas turbine burner made of inconel 718. Phys Procedia 83:761-768. https://doi.org/10.1016/j. phpro.2016.08.078

61. Ünal-Saewe T, Gahn L, Kittel J, Gasser A, Schleifenbaum JH (2020) Process development for tip repair of complex shaped turbine blades with IN718. Procedia Manuf 47:1050-1057. https:// doi.org/10.1016/j.promfg.2020.04.114

62. Foster J, Cullen C, Fitzpatrick S, Payne G, Hall L, Marashi J (2019) Remanufacture of hot forging tools and dies using laser metal deposition with powder and a hard-facing alloy Stellite $21 \circledR$. J Remanufacturing 9:189-203. https://doi.org/10.1007/s13243018-0063-9

63. Laser metal deposition (LMD). Trumpf n.d. https://www.trumpf. com/en_GB/applications/additive-manufacturing/laser-metaldeposition-lmd/ (accessed March 17, 2020).

64. Jinoop AN, Paul CP, Mishra SK, Bindra KS (2019) Laser additive manufacturing using directed energy deposition of Inconel-718 wall structures with tailored characteristics. Vacuum 166:270 278. https://doi.org/10.1016/j.vacuum.2019.05.027

65. Segerstark A, Andersson J, Svensson LE, Ojo O (2018) Effect of process parameters on the crack formation in laser metal powder deposition of alloy 718. Metall Mater Trans A Phys Metall Mater Sci 49:5042-5050. https://doi.org/10.1007/s11661-018-4767-0

66. Langebeck A, Bohlen A, Freisse H, Vollertsen F (2019) Additive manufacturing with the lightweight material aluminium alloy EN AW-7075. Weld World 64:429-436. https://doi.org/10.1007/ s40194-019-00831-z

67. Ngo TD, Kashani A, Imbalzano G, Nguyen KTQ, Hui D (2018) Additive manufacturing (3D printing): a review of materials, methods, applications and challenges. Compos Part B Eng 143: 172-196. https://doi.org/10.1016/j.compositesb.2018.02.012

68. Huang Y, Leu MC, Mazumder J, Donmez A (2015) Additive manufacturing: current state, future potential, gaps and needs, and recommendations. J Manuf Sci Eng Trans ASME 137:1-11. https://doi.org/10.1115/1.4028725

69. Khorasani AM, Gibson I, Goldberg M, Littlefair G (2017) Production of Ti-6Al-4V acetabular shell using selective laser melting: possible limitations in fabrication. Rapid Prototyp J 23: 110-121. https://doi.org/10.1108/RPJ-11-2015-0159

70. Konečná R, Nicoletto G (2019) On the link between as-built surface quality and fatigue behavior of additively manufactured Inconel 718. Procedia Struct Integr 23:384-389. https://doi.org/ 10.1016/j.prostr.2020.01.117

71. Pal S, Lojen G, Hudak R, Rajtukova V, Brajlih T, Kokol V, Drstvenšek I (2020) As-fabricated surface morphologies of Ti$6 \mathrm{Al}-4 \mathrm{~V}$ samples fabricated by different laser processing parameters in selective laser melting. Addit Manuf 33:101147. https://doi. org/10.1016/j.addma.2020.101147

72. DePond PJ, Guss G, Ly S, Calta NP, Deane D, Khairallah S et al (2018) In situ measurements of layer roughness during laser powder bed fusion additive manufacturing using low coherence scanning interferometry. Mater Des 154:347-359. https://doi.org/10. 1016/j.matdes.2018.05.050

73. Ghimire S, Flury M, Scheenstra EJ, Miles CA (2019) Benchmarking Build simulation software for laser powder bed fusion of metals. Addit Manuf 135577:135577. https://doi.org/ 10.1016/j.scitotenv.2019.135577

74. Wu Z (2020) Exploring the fabrication limits of thin-wall structures in a laser powder bed fusion process. Int $\mathrm{J}$ Adv Manuf Technol 110:191-207

75. Frazier WE (2014) Metal additive manufacturing: a review. J Mater Eng Perform 23:1917-1928. https://doi.org/10.1007/ s11665-014-0958-z

76. Selcuk C (2011) Laser metal deposition for powder metallurgy parts. Powder Metall 54:94-99. https://doi.org/10.1179/ $174329011 X 12977874589924$

77. Liou F, Slattery K, Kinsella M, Newkirk J, Chou HN, Landers R (2007) Applications of a hybrid manufacturing process for fabrication of metallic structures. Rapid Prototyp J 13:236-244. https:// doi.org/10.1108/13552540710776188

78. Schmelzle J, Kline EV, Dickman CJ, Reutzel EW, Jones G, Simpson TW (2015) (Re) Designing for part consolidation: understanding the challenges of metal additive manufacturing. $J$ Mech Des Trans ASME 137:1-12. https://doi.org/10.1115/1. 4031156

79. Du W, Bai Q, Zhang B (2016) A novel method for additive/ subtractive hybrid manufacturing of metallic parts. Procedia Manuf 5:1018-1030. https://doi.org/10.1016/j.promfg.2016.08. 067

80. Arregui L, Garmendia I, Pujana J, Soriano C (2018) Study of the geometrical limitations associated to the metallic part manufacturing by the LMD process. Procedia CIRP 68:363-368. https://doi. org/10.1016/j.procir.2017.12.096 
81. Lorenz KA, Jones JB, Wimpenny DI, Jackson MR (2014) A review of hybrid manufacturing. Igarss 2014:1-5. https://doi.org/10. 1007/s13398-014-0173-7.2

82. Bhaduri D, Penchev P, Essa K, Dimov S, Carter LN, Pruncu CI, Pullini D (2019) Evaluation of surface/interface quality, microstructure and mechanical properties of hybrid additivesubtractive aluminium parts. CIRP Ann 68:237-240. https://doi. org/10.1016/j.cirp.2019.04.116

83. Spierings AB, Levy G, Labhart L, Wegener K (2012) Production of functional parts using SLM - opportunities and limitations. Innov Dev Virtual Phys Prototyp - Proc 5th Int Conf Adv Res Rapid Prototyp 785-90. https://doi.org/10.1201/b11341-126

84. Gao W, Zhang Y, Ramanujan D, Ramani K, Chen Y, Williams CB, Wang CCL, Shin YC, Zhang S, Zavattieri PD (2015) The status, challenges, and future of additive manufacturing in engineering. CAD Comput Aided Des 69:65-89. https://doi.org/10. 1016/j.cad.2015.04.001

85. Ahuja B, Karg M, Schmidt M (2015) Additive manufacturing in production: challenges and opportunities. Laser 3D Manuf II 9353:935304. https://doi.org/10.1117/12.2082521

86. Jacob G, Brown C, Donmez A, Watson S (2017) Effects of powder recycling on stainless steel powder and built material properties in metal powder bed fusion processes. NIST Adv Manuf Ser 100:59

87. O'Leary R, Setchi R, Prickett P, Hankins G, Jones N (2015) An investigation into the recycling of Ti-6Al-4V powder used within SLM to improve sustainability. SDM'2015 2nd Int Conf Sustain Des Manuf 14-7

88. Asgari H, Baxter C, Hosseinkhani K, Mohammadi M (2017) On microstructure and mechanical properties of additively manufactured AlSi10Mg_200C using recycled powder. Mater Sci Eng A 707:148-158. https://doi.org/10.1016/j.msea.2017.09. 041

89. Ardila LC, Garciandia F, González-Díaz JB, Álvarez P, Echeverria A, Petite MM, Deffley R, Ochoa J (2014) Effect of IN718 recycled powder reuse on properties of parts manufactured by means of selective laser melting. Phys Procedia 56:99-107. https://doi.org/10.1016/j.phpro.2014.08.152

90. Pauzon C, Hryha E, Forêt P, Nyborg L (2019) Effect of argon and nitrogen atmospheres on the properties of stainless steel 316L parts produced by laser-powder bed fusion. Mater Des 179: 107873. https://doi.org/10.1016/j.matdes.2019.107873

91. Renderos M, Girot F, Lamikiz A, Torregaray A, Saintier N (2016) $\mathrm{Ni}$ based powder reconditioning and reuse for LMD process. Phys Procedia 83:769-777. https://doi.org/10.1016/j.phpro.2016.08. 079

92. Thompson MK, Moroni G, Vaneker T, Fadel G, Campbell RI, Gibson I, Bernard A, Schulz J, Graf P, Ahuja B, Martina F (2016) Design for additive manufacturing: trends, opportunities, considerations, and constraints. CIRP Ann Manuf Technol 65: 737-760. https://doi.org/10.1016/j.cirp.2016.05.004

93. Hassanin H, Modica F, El-Sayed MA, Liu J, Essa K (2016) Manufacturing of Ti-6Al-4V micro-implantable parts using hybrid selective laser melting and micro-electrical discharge machining. Adv Eng Mater 18:1544-1549. https://doi.org/10.1002/adem. 201600172

94. Essa K, Modica F, Imbaby M, El-Sayed MA, ElShaer A, Jiang K et al (2017) Manufacturing of metallic micro-components using hybrid soft lithography and micro-electrical discharge machining. Int J Adv Manuf Technol 91:445-452. https://doi.org/10.1007/ s00170-016-9655-4

95. Bhaduri D, Penchev P, Carter LN, Essa KEA, Dimov S, Adkins NJE, Bajolet J, Tommasi A, Pullini D, Jurdeczka U (2018) Development and evaluation of a hybrid additive-subtractive process chain. CIRP Winter Meet 2018
96. Popovich VA, Borisov EV, Popovich AA, Sufiiarov VS, Masaylo DV, Alzina L (2017) Impact of heat treatment on mechanical behaviour of Inconel 718 processed with tailored microstructure by selective laser melting. Mater Des 131:12-22. https://doi.org/ 10.1016/j.matdes.2017.05.065

97. Hassanin H, Essa K, Qiu C, Abdelhafeez AM, Adkins NJE, Attallah MM (2017) Net-shape manufacturing using hybrid selective laser melting/hot isostatic pressing. Rapid Prototyp J 23:720 726. https://doi.org/10.1108/RPJ-02-2016-0019

98. Kalentics N, Boillat E, Peyre P, Gorny C, Kenel C, Leinenbach C, Jhabvala J, Logé RE (2017) 3D laser shock peening - a new method for the $3 \mathrm{D}$ control of residual stresses in selective laser melting. Mater Des 130:350-356. https://doi.org/10.1016/j. matdes.2017.05.083

99. Sun R, Li L, Zhu Y, Guo W, Peng P, Cong B, Sun J, Che Z, Li B, Guo C, Liu L (2018) Microstructure, residual stress and tensile properties control of wire-arc additive manufactured 2319 aluminum alloy with laser shock peening. J Alloys Compd 747:255265. https://doi.org/10.1016/j.jallcom.2018.02.353

100. Hackel L, Rankin JR, Rubenchik A, King WE, Matthews M (2018) Laser peening: a tool for additive manufacturing post-processing. Addit Manuf 24:67-75. https://doi.org/10.1016/j.addma. 2018.09.013

101. Luo S, He W, Chen K, Nie X, Zhou L, Li Y (2018) Regain the fatigue strength of laser additive manufactured Ti alloy via laser shock peening. J Alloys Compd 750:626-635. https://doi.org/10. 1016/j.jallcom.2018.04.029

102. Guo W, Sun R, Song B, Zhu Y, Li F, Che Z, Li B, Guo C, Liu L, Peng P (2018) Laser shock peening of laser additive manufactured Ti6Al4V titanium alloy. Surf Coat Technol 349:503-510. https:// doi.org/10.1016/j.surfcoat.2018.06.020

103. Madireddy G, Li C, Liu J, Sealy MP (2019) Modeling thermal and mechanical cancellation of residual stress from hybrid additive manufacturing by laser peening. Nami Jishu Yu Jingmi Gongcheng/Nanotechnol Precis Eng 2:49-60. https://doi.org/10. 1016/j.npe.2019.07.001

104. Qiu C, Adkins NJE, Hassanin H, Attallah MM, Essa K (2015) Insitu shelling via selective laser melting: modelling and microstructural characterisation. Mater Des 87:845-853. https://doi.org/10. 1016/j.matdes.2015.08.091

105. Zhu Z, Dhokia V, Nassehi A, Newman ST (2016) Investigation of part distortions as a result of hybrid manufacturing. Robot Comput Integr Manuf 37:23-32. https://doi.org/10.1016/j.rcim.2015.06. 001

106. Airbus (2015) Airbus Technical Magazine. Flight Airworth Support Technol 34

107. Surface roughness - digital alloys. Digit Alloy n.d. https://www. digitalalloys.com/blog/surface-roughness/ (accessed May 21, 2020)

108. Calignano $F(2018)$ Investigation of the accuracy and roughness in the laser powder bed fusion process. Virtual Phys Prototyp 13:97104. https://doi.org/10.1080/17452759.2018.1426368

109. Rombouts M, Maes G, Hendrix W, Delarbre E, Motmans F (2013) Surface finish after laser metal deposition. Phys Procedia 41:810 814. https://doi.org/10.1016/j.phpro.2013.03.152

110. Rotella G, Imbrogno S, Candamano S, Umbrello D (2018) Surface integrity of machined additively manufactured Ti alloys. J Mater Process Technol 259:180-185. https://doi.org/10.1016/j. jmatprotec.2018.04.030

111. Dadbakhsh S, Hao L, Kong CY (2010) Surface finish improvement of LMD samples using laser polishing. Virtual Phys Prototyp 5:215-221. https://doi.org/10.1080/17452759.2010. 528180

112. Tucho WM, Cuvillier P, Sjolyst-Kverneland A, Hansen V (2017) Microstructure and hardness studies of Inconel 718 manufactured by selective laser melting before and after solution heat treatment. 
Mater Sci Eng A 689:220-232. https://doi.org/10.1016/j.msea. 2017.02.062

113. Deng D, Peng RL, Brodin H, Moverare J (2018) Microstructure and mechanical properties of Inconel 718 produced by selective laser melting: sample orientation dependence and effects of post heat treatments. Mater Sci Eng A 713:294-306. https://doi.org/10. 1016/j.msea.2017.12.043

114. AlMangour B, Yang JM (2016) Improving the surface quality and mechanical properties by shot-peening of 17-4 stainless steel fabricated by additive manufacturing. Mater Des 110:914-924. https://doi.org/10.1016/j.matdes.2016.08.037

115. Uzan NE, Ramati S, Shneck R, Frage N, Yeheskel O (2018) On the effect of shot-peening on fatigue resistance of AlSi10Mg specimens fabricated by additive manufacturing using selective laser melting (AM-SLM). Addit Manuf 21:458-464. https://doi.org/10. 1016/j.addma.2018.03.030

116. Maamoun A, Elbestawi M, Veldhuis S (2018) Influence of shot peening on AlSi10Mg parts fabricated by additive manufacturing. J Manuf Mater Process 2:40. https://doi.org/10.3390/ jmmp2030040

117. Damon J, Dietrich S, Vollert F, Gibmeier J, Schulze V (2018) Process dependent porosity and the influence of shot peening on porosity morphology regarding selective laser melted $\mathrm{AlSi} 10 \mathrm{Mg}$ parts. Addit Manuf 20:77-89. https://doi.org/10.1016/j.addma. 2018.01.001

118. Ma CP, Guan YC, Zhou W (2017) Laser polishing of additive manufactured Ti alloys. Opt Lasers Eng 93:171-177. https://doi. org/10.1016/j.optlaseng.2017.02.005

119. Yung KC, Xiao TY, Choy HS, Wang WJ, Cai ZX (2018) Laser polishing of additive manufactured $\mathrm{CoCr}$ alloy components with complex surface geometry. J Mater Process Technol 262:53-64. https://doi.org/10.1016/j.jmatprotec.2018.06.019

120. Zhihao F, Libin L, Longfei C, Yingchun G (2018) Laser polishing of additive manufactured superalloy. Procedia CIRP 71:150-154. https://doi.org/10.1016/j.procir.2018.05.088

121. Dos Santos Solheid J, Seifert HJ, Pfleging W (2018) Laser surface modification and polishing of additive manufactured metallic parts. Procedia CIRP 74:280-284. https://doi.org/10.1016/j. procir.2018.08.111

122. Penchev P, Bhaduri D, Carter L, Mehmeti A, Essa K, Dimov S, Adkins NJE, Maillol N, Bajolet J, Maurath J, Jurdeczka U (2019) System-level integration tools for laser-based powder bed fusion enabled process chains. J Manuf Syst 50:87-102. https://doi.org/ 10.1016/j.jmsy.2018.12.003

123. Boivie K, Dolinsek S, Homar D (2011) Hybrid manufacturing; integration of additive technologies for competitive production of complex tools and products. 15th Int Res Conf "Trends Dev Mach Assoc Technol

124. Solution heat treatment - Merriam Webster Dictionary (n.d.) https://www.merriam-webster.com/dictionary/solution heat treatment (accessed February 7, 2020).

125. Huang S, Yeong WY (2018) Laser re-scanning strategy in selective laser melting for part quality enhancement: a review. Proc Int Conf Prog Addit Manuf 2018:413-419. https://doi.org/10.25341/ D4GP4J

126. Lamikiz A, Sánchez JA, López de Lacalle LN, Arana JL (2007) Laser polishing of parts built up by selective laser sintering. Int J Mach Tools Manuf 47:2040-2050. https://doi.org/10.1016/j. ijmachtools.2007.01.013

127. Yasa E, Deckers J, Kruth JP (2011) The investigation of the influence of laser re-melting on density, surface quality and microstructure of selective laser melting parts. Rapid Prototyp J 17:312-327. https://doi.org/10.1108/13552541111156450

128. Yasa E, Kruth JP (2011) Microstructural investigation of selective laser melting 316L stainless steel parts exposed to laser re-melting.
Procedia Eng 19:389-395. https://doi.org/10.1016/j.proeng.2011. 11.130

129. Yang X, Liu J, Cui X, Jin G, Liu Z, Chen Y, Feng X (2019) Effect of remelting on microstructure and magnetic properties of $\mathrm{Fe}-\mathrm{Co}-$ based alloys produced by laser additive manufacturing. J Phys Chem Solids 130:210-216. https://doi.org/10.1016/j.jpcs.2019. 03.001

130. Wei K, Lv M, Zeng X, Xiao Z, Huang G, Liu M, Deng J (2019) Effect of laser remelting on deposition quality, residual stress, microstructure, and mechanical property of selective laser melting processed Ti-5Al-2.5Sn alloy. Mater Charact 150:67-77. https:// doi.org/10.1016/j.matchar.2019.02.010

131. Yu W, Sing SL, Chua CK, Tian X (2019) Influence of re-melting on surface roughness and porosity of AlSi10Mg parts fabricated by selective laser melting. J Alloys Compd 792:574-581. https:// doi.org/10.1016/j.jallcom.2019.04.017

132. Bruzzo F, Catalano G, Demir AG, Previtali B (2019) In-process laser re-melting of thin walled parts to improve surface quality after laser metal deposition. Key Eng Mater 813:191-196. https://doi.org/10.4028/www.scientific.net/KEM.813.191

133. Witkin D, Helvajian H, Steffeney L, Hansen W (2016) Laser postprocessing of Inconel 625 made by selective laser melting. Laser 3D Manuf III 9738:97380 W. https://doi.org/10.1117/12.2213745

134. Wang Y, Shi J (2019) Microstructure and properties of Inconel 718 fabricated by directed energy deposition with in-situ ultrasonic impact peening. Metall Mater Trans B Process Metall Mater Process Sci 50:2815-2827. https://doi.org/10.1007/s11663-01901672-3

135. Jones JB (2014) The synergies of hybridizing CNC and additive manufacturing. Tech Pap - Soc Manuf Eng TP14PUB72:1-8

136. Yamazaki T (2016) Development of a hybrid multi-tasking machine tool: integration of additive manufacturing technology with CNC machining. Procedia CIRP 42:81-86. https://doi.org/10. 1016/j.procir.2016.02.193

137. Penchev P, Bhaduri D, Dimov S, Soo SL (2014) Novel manufacturing platform for scale up production of miniaturized parts. IWMF, 9th Int Work MICROFACTORIES 2014:1-8

138. Mehmeti A, Penchev P, Lynch D, Vincent D, Maillol N, Maurath J, Bajolet J, Wimpenny D, Essa KDS (2020) Mechanical behaviour and interface evaluation of hybrid MIM/PBF stainless steel components [Submitted]. Rapid Prototyp

139. Data RUSA, Traverso CG, Schroeder AD, Polat BE, Magnus C, Blankschtein D et al. (2013) Additive manufacturing in stu stress relief - patent application publication ( 10 ) Pub . No .: US 2013/ 0165772 A1

140. Data RUSA, Traverso CG, Schroeder AD, Polat BE, Magnus C, Blankschtein D, et al. (2013) Functionally graded additive manufacturing with in situ heat treatment - patent application publication ( 10 ) Pub . No .: US 2013 / 0165772 A1

141. Liu B, Li BQ, Li Z (2019) Selective laser remelting of an additive layer manufacturing process on AlSi10Mg. Results Phys 12:982988. https://doi.org/10.1016/j.rinp.2018.12.018

142. Roehling JD, Smith WL, Roehling TT, Vrancken B, Guss GM, McKeown JT et al (2019) Reducing residual stress by selective large-area diode surface heating during laser powder bed fusion additive manufacturing. Addit Manuf 28:228-235. https://doi.org/ 10.1016/j.addma.2019.05.009

143. Kahlin M, Ansell H, Basu D, Kerwin A, Newton L, Smith B, Moverare JJ (2020) Improved fatigue strength of additively manufactured Ti6Al4V by surface post processing. Int J Fatigue 134:105497. https://doi.org/10.1016/j.ijfatigue.2020.105497

144. 10 Top Hybrid Manufacturing Companies. 3D Print MEdia Netw n.d. https://www.3dprintingmedia.network/the-top-ten-hybridmanufacturing-companies/ (accessed February 7, 2020)

145. DMG Mori. All in 1: Laser Deposition Welding \& Milling additive Manufacturing in Milling quality 2014:1-12. 
146. Multi-tasking M-H. INTEGREX i-400S AM n.d. https://www. mazakusa.com/machines/integrex-i-400 s-am/ (accessed February 7, 2020).

147. Matsuura. LUMEX Series n.d. https://www.lumex-matsuura.com/ english/lumex-avance-25 (accessed February 7, 2020).

148. LENS Systems - 3D Printing Metals n.d. https://optomec.com/3dprinted-metals/lens-printers/ (accessed February 7, 2020).

149. OPM350L - Sodick. n.d.

150. ADD+Process - IBARMIA n.d. https://www.ibarmia.com/en/ today/ibarmia-hybrid-machine-additive-combine (accessed February 7, 2020).

151. The world's first hybrid turbine blade \& turbo fan remannufacturing machine n.d.

152. Grzesik W (2018) Hybrid manufacturing of metallic parts integrated additive and subtractive processes. Mechanik 91:468-475. https://doi.org/10.17814/mechanik.2018.7.58

153. 5 axis machining center HSTM 2020. https://www.hamuel.de/en/ products/5-axis-machining-center-hstm (accessed November 26, 2020).

154. MetalFAB1 - additive industries n.d. https://www. additiveindustries.com/systems/metalfab1 (accessed February 20, 2020).

155. Metal 3D printing tools for any CNC - 3D hybrid n.d. http://www. 3 dhybridsolutions.com/ (accessed February 7, 2020).

156. 3D printing metal without melting? - Fabrisonic n.d. https:// fabrisonic.com/technology/ (accessed February 7, 2020).

157. Ambit - dextrous manufacturing n.d. http://www.hybridmanutech. com/ (accessed February 7, 2020).

158. Urhal P, Weightman A, Diver C, Bartolo P (2019) Robot assisted additive manufacturing: a review. Robot Comput Integr Manuf 59:335-345. https://doi.org/10.1016/j.rcim.2019.05.005

159. Krimpenis AA, Papapaschos V, Bontarenko E (2020) HydraX, a 3D printed robotic arm for hybrid manufacturing. Part I: Custom design, manufacturing and assembly. Procedia Manuf 51:103108. https://doi.org/10.1016/j.promfg.2020.10.016

160. Chen L, Lau TY, Tang K (2020) Manufacturability analysis and process planning for additive and subtractive hybrid manufacturing of Quasi-rotational parts with columnar features. CAD Comput Aided Des 118:102759. https://doi.org/10.1016/j.cad. 2019.102759

161. OPM250L Sodick's new OPM250L - Additive manufacturing plus $\mathrm{CNC}$ milling combined for the first time in one machine. Sodick n.d. https://www.sodick.org/products/additivemanufacturing/opm2501.html (accessed April 7, 2020).

162. OPM250L Experience creating the future ew Creat New Form n.d.

163. Matsuura's manufacturing as we learn from sample workpieces. Ser Matsuura - Lumex n.d. https://www.lumex-matsuura.com/ english/samplework (accessed April 7, 2020).

164. Additive manufacturing - The integration of additive manufacturing technology and multi-tasking machining. Mazak n.d. https:// www.mazakeu.co.uk/AM/ (accessed April 8, 2020).

165. Yasa E, Poyraz O, Cizioglu N, Pilatin S (2018) Repair and manufacturing of high performance tools by additive manufacturing. Des Prod Mach DIES/MOLDS:245-251

166. Ren L, Padathu AP, Ruan J, Sparks T, Liou FW (2006) Three dimensional die repair using a hybrid manufacturing system. 17th Solid Free Fabr Symp SFF 2006:51-9

167. Bennett J, Garcia D, Kendrick M, Hartman T, Hyatt G, Ehmann K, You F, Cao J (2019) Repairing automotive dies with directed energy deposition: industrial application and life cycle analysis. J Manuf Sci Eng Trans ASME 141. https://doi.org/10.1115/1. 4042078

168. Zhang X, Cui W, Li W, Liou F (2019) A hybrid process integrating reverse engineering, pre-repair processing, additive manufacturing, and material testing for component remanufacturing. Materials (Basel) 12. https://doi.org/10.3390/ ma12121961

169. Buchmayr B (2017) Damage, Lifetime, and Repair of Forging Dies. BHM Berg- Und Hüttenmännische Monatshefte 162:8893. https://doi.org/10.1007/s00501-016-0566-3

170. Hawryluk M, Dobras D, Kaszuba M, Widomski P, Ziemba J (2020) Influence of the different variants of the surface treatment on the durability of forging dies made of Unimax steel. Int J Adv Manuf Technol 107:4725-4739. https://doi.org/10.1007/s00170020-05357-z

171. Le VT, Paris H, Mandil G (2017) Process planning for combined additive and subtractive manufacturing technologies in a remanufacturing context. J Manuf Syst 44:243-254. https://doi. org/10.1016/j.jmsy.2017.06.003

172. Praniewicz M, Feldhausen T, Kersten S, Berez J, Jost E, Kurfess T, et al. (2019) Integrated hardfacing of Stellite-6 using hybrid manufacturing process. 314-27

173. Yin S, Yan X, Chen C, Jenkins R, Liu M, Lupoi R (2018) Hybrid additive manufacturing of Al-Ti6Al4V functionally graded materials with selective laser melting and cold spraying. J Mater Process Technol 255:650-655. https://doi.org/10.1016/j. jmatprotec.2018.01.015

174. Naebe M, Shirvanimoghaddam K (2016) Functionally graded materials: a review of fabrication and properties. Appl Mater Today 5:223-245. https://doi.org/10.1016/j.apmt.2016.10.001

175. Liu W, DuPont JN (2003) Fabrication of functionally graded TiC/ Ti composites by laser engineered net shaping. Scr Mater 48: 1337-1342. https://doi.org/10.1016/S1359-6462(03)00020-4

176. Li W, Karnati S, Kriewall C, Liou F, Newkirk J, Brown Taminger KM, Seufzer WJ (2017) Fabrication and characterization of a functionally graded material from Ti-6Al-4V to SS316 by laser metal deposition. Addit Manuf 14:95-104. https://doi.org/10. 1016/j.addma.2016.12.006

177. Chen B, Su Y, Xie Z, Tan C, Feng J (2020) Development and characterization of $316 \mathrm{~L} /$ Inconel625 functionally graded material fabricated by laser direct metal deposition. Opt Laser Technol 123: 105916. https://doi.org/10.1016/j.optlastec.2019.105916

178. Ford RG (2001) Functionally graded materials. 56. https://doi.org/ 10.1016/s0026-0657(01)80632-9

179. Oshkour AA, Osman NAA, Bayat M, Afshar R, Berto F (2014) Three-dimensional finite element analyses of functionally graded femoral prostheses with different geometrical configurations. Mater Des 56:998-1008. https://doi.org/10.1016/j.matdes.2013. 12.054

180. Ait Moussa A, Yadav R (2017) Optimization of a functionally graded material stem in the femoral component of a cemented hip arthroplasty: influence of dimensionality of FGM. J Med Eng 2017:1-10. https://oi.org/10.1155/2017/3069351

181. Sadollah A, Bahreininejad A, Eskandar H, Hamdi M (2013) Optimum material gradient for functionally graded dental implant using particle swarm optimization. Adv Mater Res 647:30-36. https://doi.org/10.4028/www.scientific.net/AMR.647.30

182. Swaminathan K, Sangeetha DM (2017) Thermal analysis of FGM plates - a critical review of various modeling techniques and solution methods. Compos Struct 160:43-60. https://doi.org/10. 1016/j.compstruct.2016.10.047

183. Ramakrishnan A, Dinda GP (2019) Functionally graded metal matrix composite of Haynes 282 and $\mathrm{SiC}$ fabricated by laser metal deposition. Mater Des 179:107877. https://doi.org/10.1016/j. matdes.2019.107877

184. Siva Prasad H, Brueckner F, Volpp J, Kaplan AFH (2020) Laser metal deposition of copper on diverse metals using green laser sources. Int J Adv Manuf Technol 107:1559-1568. https://doi. org/10.1007/s00170-020-05117-z

185. Strong D, Sirichakwal I, Manogharan GP, Wakefield T (2017) Current state and potential of additive - hybrid manufacturing for 
metal parts. Rapid Prototyp J 23:577-588. https://oi.org/10. 1108/RPJ-04-2016-0065

186. Shunmugavel M, Polishetty A, Nomani J, Goldberg M, Littlefair G (2016) Metallurgical and machinability characteristics of wrought and selective laser melted Ti-6Al-4V. J Metall 2016:110. https://doi.org/10.1155/2016/7407918

187. Milton S, Morandeau A, Chalon F, Leroy R (2016) Influence of finish machining on the surface integrity of Ti6Al4V produced by selective laser melting. Procedia CIRP 45:127-130. https://doi. org/10.1016/j.procir.2016.02.340

188. López de Lacalle Marcaide LN, Sánchez Galíndez JA, Lamikiz Menchaca A (2004) Mecanizado de alto rendimiento. Ediciones

189. Choudhury I, El-Baradie M (1998) Machinability of nickel-base super alloys: a general review. J Mater Process Technol 77:278284. https://doi.org/10.1016/S0924-0136(97)00429-9

190. Sharman ARC, Hughes JI, Ridgway K (2004) Workpiece surface integrity and tool life issues when turning Inconel 718 (TM) nickel based superalloy. Mach Sci Technol 8:399-414. https://doi.org/ 10.1081/LMST-200039865

191. Zaman HA, Sharif S, Kim DW, Idris MH, Suhaimi MA, Tumurkhuyag Z (2017) Machinability of cobalt-based and cobalt chromium molybdenum alloys - a review. Procedia Manuf 11: 563-570. https://doi.org/10.1016/j.promfg.2017.07.150

192. Oyelola O, Crawforth P, M'Saoubi R, Clare AT (2016) Machining of Additively manufactured parts: implications for surface integrity. Procedia CIRP 45:119-122. https://doi.org/10.1016/j.procir. 2016.02.066

193. Hojati F, Daneshi A, Soltani B, Azarhoushang B, Biermann D (2020) Study on machinability of additively manufactured and conventional titanium alloys in micro-milling process. Precis Eng 62:1-9. https://doi.org/10.1016/j.precisioneng.2019.11.002

194. Aldwell B, Kelly E, Wall R, Amaldi A, O’Donnell GE, Lupoi R (2017) Machinability of Al 6061 Deposited with cold spray additive manufacturing. J Therm Spray Technol 26:1573-1584. https://doi.org/10.1007/s11666-017-0586-x

195. Calleja A, Urbikain G, González H, Cerrillo I, Polvorosa R, Lamikiz A (2018) Inconel®718 superalloy machinability evaluation after laser cladding additive manufacturing process. Int J Adv
Manuf Technol 97:2873-2885. https://doi.org/10.1007/s00170018-2169-5

196. Cortina M, Arrizubieta JI, Ruiz JE, Ukar E, Lamikiz A (2018) Latest developments in industrial hybrid machine tools that combine additive and subtractive operations. Materials (Basel) 11 . https://doi.org/10.3390/ma11122583

197. Paul R, Anand S, Gerner F (2014) Effect of thermal deformation on part errors in metal powder based additive manufacturing processes. J Manuf Sci Eng Trans ASME 136. https://doi.org/10. $1115 / 1.4026524$

198. Das P, Chandran R, Samant R, Anand S (2015) Optimum part build orientation in additive manufacturing for minimizing part errors and support structures. Procedia Manuf 1:343-354. https://doi.org/10.1016/j.promfg.2015.09.041

199. Eisenbarth D, Soffel F, Wegener K (2019) Effects of direct metal deposition combined with intermediate and final milling on part distortion. Virtual Phys Prototyp 14:130-134. https://doi.org/10. 1080/17452759.2018.1532799

200. Lu QY, Wong CH (2017) Applications of non-destructive testing techniques for post-process control of additively manufactured parts. Virtual Phys Prototyp 12:301-321. https://doi.org/10.1080/ 17452759.2017.1357319

201. Montinaro N, Cerniglia D, Pitarresi G (2018) Defect detection in additively manufactured titanium prosthesis by flying laser scanning thermography. Procedia Struct Integr 12:165-172. https:// doi.org/10.1016/j.prostr.2018.11.098

202. Hebert RJ (2016) Viewpoint: metallurgical aspects of powder bed metal additive manufacturing. J Mater Sci 51:1165-1175. https:// doi.org/10.1007/s10853-015-9479-x

203. (Renishaw) MS. Meeting the machining challenges of additive manufacturing. Mod Mach Shop 2017. https://www.mmsonline. $\mathrm{com} /$ articles/meeting-the-machining-challenges-of-additivemanufacturing (accessed April 8, 2020).

Publisher's Note Springer Nature remains neutral with regard to jurisdictional claims in published maps and institutional affiliations. 